\title{
3D mesoscale modeling and fracture property study of rubberized self- compacting concrete based on uniaxial tension test
}

Dol:

10.1016/j.tafmec.2019.102363

\section{Document Version}

Accepted author manuscript

Link to publication record in Manchester Research Explorer

Citation for published version (APA):

Li, X., Chen, X., Jivkov, A., \& Zhang, J. (2019). 3D mesoscale modeling and fracture property study of rubberized self- compacting concrete based on uniaxial tension test. Theoretical and Applied Fracture Mechanics, 104, 1-14. [102363]. https://doi.org/10.1016/j.tafmec.2019.102363

\section{Published in:}

Theoretical and Applied Fracture Mechanics

\section{Citing this paper}

Please note that where the full-text provided on Manchester Research Explorer is the Author Accepted Manuscript or Proof version this may differ from the final Published version. If citing, it is advised that you check and use the publisher's definitive version.

\section{General rights}

Copyright and moral rights for the publications made accessible in the Research Explorer are retained by the authors and/or other copyright owners and it is a condition of accessing publications that users recognise and abide by the legal requirements associated with these rights.

\section{Takedown policy}

If you believe that this document breaches copyright please refer to the University of Manchester's Takedown Procedures [http://man.ac.uk/04Y6Bo] or contact uml.scholarlycommunications@manchester.ac.uk providing relevant details, so we can investigate your claim.

\section{OPEN ACCESS}




\section{D mesoscale modeling and fracture property study of rubberized}

\section{2 self-compacting concrete based on uniaxial tension test}

\section{8}

Xing Li ${ }^{\mathrm{a}, \mathrm{b}}$, Xudong Chen ${ }^{\mathrm{a} *}$, Andrey P Jivkov ${ }^{\mathrm{c}}$, Jinhua Zhang ${ }^{\mathrm{d}}$

${ }^{a}$ College of Civil and Transportation Engineering, Hohai University, Nanjing, 210098, P.R. China

${ }^{\mathrm{b} C o l l e g e}$ of Water Conservancy and Hydropower Engineering, Hohai University, Nanjing, 210098, P.R. China

'Department of Mechanical, Aerospace and Civil Engineering, The University of Manchester, Manchester, M13 9PL, UK

dSchool of Civil Engineering, Southeast University, Nanjing, 210096, P.R. China

Abstract: Rubberized concrete is a new type of building material intended to ultise

waste rubber with a potential for significant economic and environmental benefits.

However, its strength is lower than the strength of ordinary concrete due to the

introduction of rubber material, which might affect its application in practical

engineering. To improve the mechanical performance of rubberized self-compacting

concrete (RSCC), it is a necessary to study the internal mechanisms of strength

formation, degradation and failure. Based on the uniaxial tensile test of RSCC, this

work reports on the development and validation of a mesoscale model of RSCC, which

accounts for its heterogeneity. RSCC is considered to be composed of mortar, coarse

1 aggregate, rubber particles, aggregate-mortar interface transition zone (A-M ITZ),

22 rubber particle-mortar interface transition zone (R-M ITZ), and initial defects. The

3 mesoscopic model is validated by comparing the simulation results with test results.

\footnotetext{
${ }^{*}$ Corresponding author

E-mail: cxdong1985@hotmail.com
} 
24 The model is then used to analyse the mechanical properties, crack generation and

25 propagation, and expansion of self-compacting concrete (SCC) and RSCC are

26 compared and analysed. Further, the effects of different volume fractions of rubber on

27 the mechanical properties of RSCC are studied. It is found that the mechanical

28 properties and final fracture surface morphology of RSCC with different rubber content

29 are significantly different, and the causes of these differences are discussed.

30 Keywords: RSCC; R-M ITZ; Uniaxial tensile test; 3D mesoscale model; Fracture

31 property; Crack morphology

\section{Introduction}

33 Nowadays, waste rubber, predominantly from used tires, has become the second-largest

34 polymer pollutant and its disposal has attracted increasing attention across countries and governments. The treatment of waste rubber generally included physical processing, chemical decomposition, stacking, landfill, and combustion. Among these, landfill, burning, and chemical decomposition are very harmful to the environment, and natural placement cannot clear up the waste rubber for a short period. An effective method to deal with the waste rubber is by crushing used tires and adding them into rubberized concrete after physical processing. Rubberized concrete can effectively solve the

41 problem of disposal of rubber products such as used tires and has unique advantages in environmental protection. 
44 are used to replace the coarse and fine aggregates inside the concrete by equal volume 45 or equal mass. The incorporation of rubber particles changes concrete properties from 46 the known properties of plain concrete. Eldin [1], Toutanji [2], Topcu [3], Guoqiang li 47 [4], F. Hernandez [5,6] demonstrated experimentally that with the increase of rubber content, the compressive strength, flexural strength and tensile strength of concrete specimens decreased, while plastic properties improved significantly. L.Zheng [7], Feng Liu [8] studied the seismic performance of rubberized concrete by vibration test.

51 The test results showed that the damping ratio of rubber concrete was much higher than the ordinary concrete, and the dynamic elastic modulus was lower than the ordinary concrete. Wang her Yung [9] studied the durability of RSCC through experiments. The results showed that the toughness and durability of RSCC could be significantly improved when the rubber content was 5\%. These scholars have made many contributions to explore the property of rubberized concrete and expand the engineering utilization of rubberized concrete. A common conclusion from their research is that the incorporation of rubber can significantly improve the apparent density, durability, shock absorption, impact resistance, heat insulation, sound insulation, and other properties of concrete but at the same time its strength will decline substantially. To improve the

61 strength of rubberized concrete, the crack pattern and failure mechanism need to be 62 studied and understood in sufficient detail, e.g. via explicit representation of its 63 constituents using meso-scale models. However, little attention has been given to this 64 type of modelling of rubberized concrete[10]. One of the very few contributions is the 
work by Feng Liu [11] who considered the rubberized concrete as a composite of aggregate, rubber and mortar, which however is quite different from the actual rubberized concrete where interfacial transition zones(ITZs) are known to control damage initiation and propagation. Another notable work is by ZH Xie [12], who analysed the mechanical properties of rubberized concrete by a $2 \mathrm{D}$ model, where the material contained four phases: aggregate, rubber, mortar, and aggregate-mortar interface. This work, however, omitted explicit representation of the phase with weakest mechanical properties, namely R-M ITZ. Furthermore, 2D analysis is not a reliable approach to studying the complex crack patterns forming in real materials. To the best of our knowledge, a study regarding rubberized concrete as a six-phases material composed of aggregate, rubber, mortar, voids, A-M ITZ, R-M ITZ, in a 3D mesoscale heterogeneous model has not been proposed to date. Such a study would allow for substantially more realistic representation of the rubberized concrete mesostructure and correspondingly more reliable analysis and discussion of its mechanical properties. In this paper, appropriate 3D meso-scale model is proposed and validated using uniaxial tensile tests. The model is used to investigate the crack formation mechanism and mechanical properties of rubberized concrete.

The paper is organised as follows. Uniaxial tension tests of rubberized selfcompacting concrete with different rubber particle content are presented in Section 2. Based on the test results, a 3D mesoscale model of rubberized self-compacting concrete is established and presented in Section 3. The parameters and constitutive law of the 
$3 \mathrm{D}$ model are determined by the test results and trial calculations. Model validation is performed in Section 4, where comparison between simulations and experiments is shown. Section 5 presents parametric studies investigating the effects of rubber content on the strength, crack initiation, crack propagation and fracture morphology. Both test results and simulation results show that the toughness of RSCC is improved compared with that of SCC without rubber particle. The incorporation of rubber particles reduces the failure rate of the whole prism and controls the final fracture morphology of the uniaxial tensile cracks of RSCC.

\section{Experiment programme}

\subsection{Materials}

The exact mix proportions of RSCC used in this paper are shown Table 1. The materials used are listed as follows: P.O.42.5 plain Portland cement with a density of 2600 $\mathrm{kg} / \mathrm{m}^{3}$; gravel with size distribution shown in Table 2; river sand; rubber particles with a density of $1050 \mathrm{~kg} / \mathrm{m}^{3}$; fly ash; silica fume; highly efficient polycarboxylate water reducer; tap water. Fine rubber particles were produced by mechanical shredding of waste tire. These particles were sieved, and the particles with a size ranging from $3 \sim 5 \mathrm{~mm}$ retained. The fine aggregate of concrete is replaced by the sieved rubber particles in the volume of $0 \%, 5 \%, 10 \%$, and $15 \%$, respectively. The specimens with fine aggregates was replaced with $0 \%, 5 \%, 10 \%, 15 \%$ rubber particles were designated by RSCC-0, RSCC-5, RSCC-10 and RSCC15, respectively. 


\subsection{Specimen production}

107 Prescribed amounts of material according to the mix proportion - fine aggregate, cement,

108 fly ash and silica fume - were added and mixed for the 30 s in the concrete mixer. This

109 was followed by coarse aggregate addition and to thorough stirring. Finally, the tap

110 water, water reducer and rubber particles were added and mixed for 3 minutes. The

111 produced fresh concrete was discharged and poured into plastic molds with dimensions

112 of $100 \mathrm{~mm} \times 100 \mathrm{~mm} \times 400 \mathrm{~mm}$. The molds were removed after $24 \mathrm{~h}$. Then

113 specimens were cured in water for 28 days. As mentioned before, four groups specimen

114 with different rubber content were prepared.

\section{$115 \quad 2.3$ Specimen processing}

116 According to the previous studies $[13,14]$, when the cross-section of a prism specimen

117 is kept constant, the measured tensile strength of the prism decreases with the increasing

118 of prism length of the prism due to size effect. However, when the aspect ratio of

119 prismatic specimens is $3 \sim 4$, the measured tensile strength tends to be a constant. At the

120 same time, due to the clamping method used in this paper, the stress distribution in the

121 test piece is very uniform for a specimen with a length greater than $200 \mathrm{~mm}$. Thus, the

122 length of the specimen was selected to be $300 \mathrm{~mm}$. Before the test, the specimens were

123 taken out from the curing pool and their lengths reduced by cutting off $50 \mathrm{~mm}$ from both

124 ends. The specimens were cleaned up and steel plates with the same size were attached

125 at both ends using adhesive glue. The tensile strength of the glue used is not less than 
$12610 \mathrm{MPa}$, which is higher than the tensile strength of the concrete specimen, ensuring that

127 it will not be degummed during the tensile test. The steel plate was connected to the

128 testing machine through the ball hinge, as shown in Fig. 1. The horizontal ruler was

129 used for calibration in the process of pasting the steel plate to avoid the influence of

130 eccentricity. The positioning hole on the pasted steel plate was located at the section

131 centroid of the specimen to ensure the geometric alignment of the tensile test.

\section{$132 \quad 2.4$ Experimental procedure}

133 A 500kN MTS322 electro-hydraulic servo testing machine was adapted for loading,

134 and the specimen was connected to the testing machine through ball hinge. The test

135 machine was equipped with an extensometer (standard gauge $280 \mathrm{~mm}$, measuring range

$136 \pm 2.5 \mathrm{~mm}$ ), which could measure the deformation of the recorded test piece and could

137 also be used to control the test loading process. The extensor installation diagram is

138 shown in Fig. 1.

139 The deformation of the specimen was used as a control signal in the test loading to

140 obtain the full tensile stress-strain tensile curve. During the test, the load sensor of MTS

141 was used to measure the direct tension of the specimen, and the extensometer was

142 adopted to measure the deformation of the specimen. 

setup

\subsection{CDP Constitutive model}

146 Under the external load of the concrete, in addition to the stiffness degradation

147 phenomenon caused by damage, unrecoverable permanent plastic deformation will

148 also occur. In recent years, many researchers have applied the two theoretical

149 frameworks of plasticity and damage to characterize the mechanical behavior of

150 concrete, such as Grassl [15], Badel [16], and Kim et al. [17]. The plastic-damage

151 model of concrete proposed by Lubliner et al. [18] and improved by Lee and Fenves

152 [19] can not only characterize the permanent plastic deformation of concrete under

153 external load but also describe the stiffness degradation caused by damage

154 accumulation of concrete and the mechanical behavior of material softening after

155 reaching peak strength. The main idea of the concrete damage model is to assume that

156 the failure pattern of concrete is cracking during tension and crushing under

157 compression. The isotropic damage variable is used to characterize the stiffness

158 degradation and unrecoverable plasticity caused by a tensile fracture and compression

159 failure of concrete. This is described mathematically by:

160

$$
\sigma=(1-D) D_{0}^{e l}:\left(\varepsilon-\varepsilon^{p l}\right)
$$

161 where D represents the isotropic damage variable; $\mathrm{D}_{0}^{e l}$ is the initial linear isotropic

162 elastic modulus; $\varepsilon^{\mathrm{pl}}$ represents the plastic strain tensor. The evolution of plasticity is 
163 described by two hardening parameters, $\tilde{\varepsilon}_{\mathrm{t}}^{\mathrm{Pl}}$ and $\tilde{\varepsilon}_{\mathrm{c}}^{\mathrm{Pl}}$, where footers " $\mathrm{t}$ " and "c"

164 respectively represent tension and compression. Figures 2 (a) and (b) respectively

165 show the mechanical behaviour of concrete under uniaxial compression and tension.

166 Under tension, the material is linear elastic before reaching its strength $f_{t}$, and the

167 stiffness degradation occurs after exceeding the tensile strength. The softening stress-

168 displacement relation characterizes the stiffness degradation behaviour. Under

169 compression, the material is linear elastic before reaching a yield strength, typically

$17040 \% \sim 60 \%$ of the compressive strength. When the stress is larger than the yield stress

171 but less than the peak stress, the material is in a strain hardening regime. After

172 exceeding the compressive strength (peak stress), strain softening, and stiffness

173 degradation occur. Uniaxial tensile and compressive stress-strain relationships can be

174 described in the form of stress and plastic strain, as follows:

$$
\begin{aligned}
& \sigma_{t}=\sigma_{t}\left(\widetilde{\varepsilon}_{t}^{p l}, \dot{\widetilde{\varepsilon}}_{t}^{p l}, \theta, \mathrm{f}_{\mathrm{i}}\right) \\
& \sigma_{c}=\sigma_{c}\left(\widetilde{\varepsilon}_{c}^{p l}, \dot{\widetilde{\varepsilon}}_{c}^{p l}, \theta, \mathrm{f}_{\mathrm{i}}\right)
\end{aligned}
$$

177 where $\dot{\widetilde{\varepsilon}}_{t}^{p l}$ and $\dot{\widetilde{\varepsilon}}_{c}^{p l}$ is the equivalent plasticity strain rate of tension and compression,

178 respectively; $\theta$ is temperature; $f_{i}(i=1,2, \ldots)$ is custom field variable.

Under uniaxial tension and compression, the stiffness degradation of concrete

180 materials is defined by two independent uniaxial damage variables, namely the tensile

181 damage factor $d_{t}$ and the compression damage factor $d_{c}$. The stress-strain

182 relationship of the material under uniaxial tension and compression conditions

183 corresponds to Fig. 2, and the expressions are: 


$$
\begin{gathered}
\sigma_{\mathrm{t}}=\left(1-\mathrm{d}_{\mathrm{t}}\right) \mathrm{E}_{0}\left(\varepsilon_{\mathrm{t}}-\tilde{\varepsilon}_{t}^{p l}\right) \\
\sigma_{\mathrm{c}}=\left(1-\mathrm{d}_{\mathrm{c}}\right) \mathrm{E}_{0}\left(\varepsilon_{\mathrm{c}}-\tilde{\varepsilon}_{c}^{p l}\right)
\end{gathered}
$$

\subsection{Generation of RSCC 3D mesoscale model}

187 Since the study of RSCC mesoscale model is uncommon, this paper attempts to

188 simulate the RSCC uniaxial tension test with a 3D mesoscale model for the first time

189 and explores other mechanical properties of RSCC through the established model.

190 The difficulty in establishing the 3D mesoscale model is that due to the

191 incorporation of rubber particles, a transitional zone between the rubber and the mortar

192 will be formed which is similar to the interface between the mortar and the coarse

193 aggregate. The nature of the interface transition zone between mortar and aggregate has

194 always been a hot topic of scholars. Nowadays, many scholars [17,20-24] regard the

195 interface transition zone between mortar and aggregate as a material similar to mortar,

196 but its porosity is much higher than mortar. Due to the existence of natural defects such

197 as voids and pores, it has always been a weak area of the overall structure. According

198 to the research of [5], the thickness of R-M ITZ is around 60 microns. And the thickness

199 of A-M ITZ is about 10 50 microns [25-27]. Therefore, the thickness of the R-M ITZ

200 is similar to that of the A-M ITZ. During the process of simulation, the most common

201 way is to treat the A-M ITZ as a thin layer of a certain thickness outside the aggregate.

202 Most scholars believed that the thickness of the A-M ITZ is fixed [21,23,28,29], while

203 H. Chen [30] thought that the thickness of the A-M ITZ varies with the size of the 

to explore the mesoscale model of RSCC, the influence of the ITZ on the properties of

206 the material is not the focus. Therefore, the thickness of A-M ITZ and R-M ITZ are all

207 taken as $0.25 \mathrm{~mm}$ to facilitate mesh generation and simulation calculation. In this paper, 208 coarse aggregate and rubber are assumed to be linear elastic materials, while mortar, A-

209 M ITZ, and R-M ITZ are defined as plastic-damaged materials, which all obey the CDP

210 constitutive model described above albeit with different parameters [28,29].

211 Many scholars have explored the method of establishing the mesoscale concrete 212 model [31-34] and used a variety of ways to generate aggregate particles and voids in

213 the concrete matrix. Generally, there are two specific methods to build the mesoscopic

214 model, one is a synthetic parameterization method, and the other is an image-based

215 modelling method. In the first method, the particles are randomly placed in the space

216 according to a pre-arranged particle distribution. The limitation of this method is the

217 position and size distribution of the aggregate are different from the actual concrete

218 specimen. But it has the advantage of an easy implement. The most significant

219 advantage of the second method is that the model is generated by X-ray tomography

220 (XCT) 2D image, and the created model has the same mesostructure with the test

221 sample. This method can reconstruct a series of 2D images into a 3D structure, and

222 further mesh and rebuild them into finite element models. The most significant

223 disadvantage of the second method is time-consuming and expensive, and the 224 reconstructed finite element model tends to be unable to perform further numerical 
225 simulation and analysis due to a large number of elements. In this paper, the synthetic

226 parameterization method is used to generate the model with insufficient aggregate and

227 rubber particle distribution information, and then the generated 3D mesostructure is

228 transformed into a pixel-based image. Finally, the finite element model is generated by

229 an image-based method. The shape of the particles in this paper is all spheres to simplify

230 the mesoscale model.

231 The aggregate in concrete can be divided into coarse aggregate and fine aggregate,

232 only coarse aggregate is considered in the model, and fine aggregate is composed of

233 mortar together with cement. The particle size distribution of the coarse aggregate in

234 the model is consistent with the experimental gradation setting, as shown in Table 2.

235 The rubber particles are also kept consistent with the experimental setup; all the rubber

236 particle size is in the range of $3 \sim 5 \mathrm{~mm}$. Pores and voids are weak areas of concrete, and

237 the presence of pores and voids can provide a channel for the development of cracks.

238 Therefore, to fully reflect the mesostructure of concrete, the pores and voids should also

239 be included in the mesoscopic model. According to the CT scan results [35], the pore

240 size range is $1 \sim 2 \mathrm{~mm}$, and the porosity of SCC is $1 \% \sim 3 \%$. So, in this paper, the porosity

241 of the mesoscale model is set as 1\%. Similarly to Ref. [24], finite-thickness A-M ITZ

242 and R-M ITZ elements are generated by enlarging aggregates and rubber particles

243 before the model is tessellated into voxels. Enlargement by radius increment of 0.25

$244 \mathrm{~mm}$ is used for A-M ITZ and R-M ITZ.

245 The critical technology for model generation is the need to repeatedly generate 
246 aggregates, rubber particles, and voids until the content of these three components

247 reaches a predetermined volume fraction. The whole process of particle filling consists

248 of three procedures: input- taking- placing. The input procedure is to input the dominant

249 information to generate randomly distributed aggregate, rubber particles, and voids

250 structure. The taking process produces aggregates, rubber particles, and pores

251 consistent with the random size and distribution demand. All the generated particles are

252 then placed into pre-defined areas irregularly and randomly according to pre-set

253 physical boundaries of the specimen. When placing particles into a given area, the

254 essential principle is that the aggregate, rubber particles, and pores cannot intersect or

255 overlap. In this paper, a direct, effective and easy method to implement 3D spherical

256 overlap detection is proposed which can be easily fulfilled by meeting the following

257 three requirements: (1) each particle must be contained within the volume of the

258 concrete, which can be satisfied by controlling the maximum and minimum values of

259 the particle coordinates; (2) there is no overlapping and intersect between all particles;

260 (3) the distance between all particles and the boundary of the concrete specimen should

261 be within a specific range, and the particles do not intersect with the concrete boundary.

262 As shown in Equation (4), for two sphere particles, the intersection and overlap

263 conditions can be easily checked by comparing the particle centre distance and the sum

264 of the two radii.

$$
\sqrt{\left(\mathrm{x}_{0}^{\prime}-\mathrm{x}_{0}\right)^{2}+\left(\mathrm{y}_{0}^{\prime}-\mathrm{y}_{0}\right)^{2}+\left(\mathrm{z}_{0}^{\prime}-\mathrm{z}_{0}\right)^{2}} \leq \mathrm{r}+r^{\prime}
$$

$266 \mathrm{x}_{0}, \mathrm{y}_{0}, \mathrm{z}_{0}$ are the center coordinates of the existed sphere, $\mathrm{r}$ is the radius of the sphere, 
$267 \mathrm{x}_{0}^{\prime}, \mathrm{y}_{0}^{\prime}, \mathrm{z}_{0}^{\prime}$ are the center coordinates of the newly generated sphere, and $\mathrm{r}^{\prime}$ is the 268 radius of the newly generated sphere.

269 Based on the above algorithm, a MATLAB code is compiled to generate concrete 270 specimens with randomly distributed aggregates, rubber particles, and voids. The flow 271 chart of the code to generate random particles is shown in Fig. 3.

272 To reduce the number of three-dimensional model elements and improve the 273 computational efficiency, the size of the 3D model specimens was set as $27450 \mathrm{~mm} \times 50 \mathrm{~mm} \times 150 \mathrm{~mm}$, half of the test specimens. In this paper, four groups of 275 mesoscale numerical models were generated with the same composition and particle 276 gradation as in the test specimens. As shown in Fig. 4, the aggregate and rubber content 277 of the mesoscale model is the same in the test specimen.

\section{$278 \quad 3.3$ Uniaxial tensile simulation of the concrete prism}

279 The uniaxial tensile test of the concrete prism is conducted by the electro-hydraulic

280 servo tester simultaneously applies a tension force to the specimen at both ends

281 through a ball hinge. In the numerical simulation, to obtain the stress-strain

282 relationship from the simulation results, the specimen was fixed at one end, and the

283 displacement load was applied on all nodes at the other end. The solution was

284 obtained through the standard analysis of Abaqus. The simulation parameters used in

285 this paper are shown in Table 3. Similar to previous works [13,15,21,31-33], it is

286 assumed that the aggregate is linear elastic material which will not be damaged, and 
the crack will not develop inside the aggregate. The rubber is originally an elastic

material, and its material parameters maintain its inherent material properties. The

selection of mortar parameters is inferred from the test results of SCC without adding

rubber. The study on the R-M ITZ parameters is not so common, but the study of [5]

291 shows the porosity of the R-M ITZ is quite larger than that of the A-M ITZ, and the

microstructure is worse than that of the A-M ITZ. It can be inferred that the

mechanical properties of the R-M ITZ are worse than the A-M ITZ. The parameters of

the A-M ITZ and the parameters of the R-M ITZ are obtained by referring to the parameters in literature $[11,12,15,24,33]$ and through trial calculation. The rationality of the parameters used in this paper is verified by comparing the test and the simulation results in section 4.

\section{Comparison of test results with numerical simulation results}

One of the RSCC- 0 tensile tests failed during the testing process, so there was only one effective test result of the RSCC-0 specimen. All the other specimen group has two sets of test results, which can be used for validation. To prevent the low reliability of simulation results caused by the difference in composition and the random distribution of aggregate and rubber particle of a single model, three random

304 mesoscale models of each component were selected for numerical simulation. The comparison of numerical simulation results and test results of each specimen group is

306 shown in Fig. 5, and the crack pattern and location of the test specimen and simulation specimen are shown in Fig. 6. 
309 test result is very high before the peak stress, indicating that the selected elastic modulus

310 is appropriate. The uniaxial tensile strength of the numerical simulation results is

311 basically within the range of the two groups of tests results. Moreover, the dispersion

312 of the uniaxial tensile strength of the three random mesoscale models is minimal,

313 indicating that the numerical model has a superior performance for predicting the

314 uniaxial tensile strength. The concrete specimen is damaged quickly after the peak

315 stress, and the strength decreases rapidly, but due to the diverse distribution of aggregate

316 and rubber particles, the difference between the mesoscale model and actual

317 components of the concrete prism, the simulation results of the post-peak period has

318 slight difference with the test results. It can also be seen from the test curves of Fig. 5

319 (b), (c) and (d) that due to the different internal composition and aggregate, rubber

320 particle distribution, the test results of two concrete specimens of the same component

321 also have dispersion in the post-peak section. After reaching the ultimate strength, the

322 micro-cracks in the concrete gather rapidly, nucleation, develop into macroscopic

323 cracks, and eventually lead to the final failure of the whole structure. The development

324 of cracks is closely related to the distribution of aggregates, rubber particles, defects

325 and voids of the specimen itself. The existence of defects and voids can provide a

326 development channel for cracks and promote its development rate. So the stress-strain

327 response after the peak stress of different specimen will be different, but the overall

328 development trend of the stress-strain curve is similar. In conclusion, the proposed 
329 3D mesoscale model can reflect the properties and the overall performance of RSCC;

330 the simulation elastic modulus is very consistent with the elastic modulus of the

331 material itself; the material strength floats in a certain error range. The material

332 performance of the post-peak section has slight discrepancy due to the different

333 components and aggregate distribution of the specimen. The global trend of the stress-

334 strain curve is consistent with the test results, which shows that the proposed 3D

335 mesoscale model in this paper can produce the overall performance of RSCC and

336 verified the feasibility of the proposed model. As can be seen from Fig. 6, the position

337 and morphology of the cracks in the numerical simulation results are very close to the

338 experimental results, which supports that the 3D mesoscale simulation results are 339 reasonable and reliable.

\section{5. Discussion}

\subsection{Effect of rubber content on the tensile strength of RSCC}

342 Figure 7 shows all the test results of RSCC under uniaxial tension. A conclusion

343 can be drawn from the figure that as the rubber content increases, the peak stress of

344 the specimen decreases, while the strain corresponds to the peak stress of the

345 specimen increases, indicating that with the increase of rubber content, the material

346 strength decreases, and toughness slightly increases. Due to the test conditions, the

347 environment influence, and the different structure of each specimen, the test results

348 have a certain degree of dispersion. From Fig. 6, the numerical simulation results 

consistent with the test results. A numerical simulation result was randomly selected

351 from each group of all the simulation results and plotted in Fig. 8 (a) to facilitate 352 the discussion and analysis of the simulation results. It can be seen in Fig. 8(a) that 353 the elastic modulus of the material decreases with the increase of rubber content 354 before the peak stress. The material strength decreases clearly with the increase of 355 rubber content, while the corresponding peak strain increases, and the material 356 toughness increases. With the increase of rubber content, the failure speed of the 357 material decreased during the post-peak period. The strength of the RSCC is 358 decreased, and the peak strain is significantly improved as compared with the 359 reference SCC (concrete without rubber particles). For all RSCC specimens, the 360 strength of the specimen decreases as the rubber content increases, and the peak 361 strain increases as the rubber particle content increases. The reason for the above 362 test and simulation results is that the addition of rubber particles in the concrete can 363 increase the toughness of the concrete but reduce the strength simultaneously. The 364 reason for the toughness enhancement of concrete is that the size of rubber particles 365 is small, which can fill the defects and voids of concrete. Besides, the rubber 366 particles can also play a role in optimizing the gradation of fine aggregate and coarse 367 aggregate. The elastic modulus of rubber is smaller than all the other components; 368 rubber can effectively relieve the stress concentration at the tip of the crack, thus 369 slowing down the expansion of cracks and enhancing the toughness of concrete 

equivalent to introducing new initial defects into the concrete due to the small elastic modulus of rubber. Rubber belongs to the organic materials; the concrete belongs to the inorganic materials. The different material type makes the cohesion at the interface transition zone between rubber and mortar weaker. The rubber particle can also play the role of air-entraining agent; the addition of rubber particle

\subsection{Effect of rubber content on crack development}

\subsubsection{Analysis of microcrack development}

381 Due to the limitation of test detection technology, it is impossible to observe and analyze the development of internal cracks of concrete in the process of tensile failure. Therefore, the development process of internal cracks of concrete is compared and analyzed using mesoscale simulation technology. After verifying the reliability of the simulation results through the comparison between the above test results and the simulation results, the simulated specimens which are consistent with the specimen setting and have good crack morphology development are selected for comparative analysis on the development of micro-cracks. Figures 9, 10,11 , and 12 show the development and distribution of microcracks in the four 
391 loading times for the four different models under uniaxial tension. Figures 10 (a),

39211 (a) and 12 (a) have one additional point, $p_{0}$, compared with Figure. 9(a). This is 393 the point where microcracks appear in specimens containing rubber, while no 394 microcracks that can be seen by the naked eye at the same loading time in ordinary 395 SCC. This is further demonstrated in Figs. 9 (b), 10 (b), 11 (b) and 12 (b), where 396 microcracks of RSCC appear earlier than the SCC specimen under the same load. 397 The green and red parts in these figures represent increasing degree of damage, i.e. 398 microcrack generation. Additionally, it is shown that the number of microcracks in 399 RSCC specimen is great than that of SCC specimen, and the degree of damage in $400 \quad$ RSCC is larger at the same loading time point.

401 During the initial stage, shown by points $p_{1}, p_{2}, p_{3}$ in Figs. 9 (b), 10 (b), 11 (b) 402 and 12 (b), microcracks appear in the weakest parts of the specimens - the ITZs. 403 With microcracks extension and coalescence one of these develops into the main 404 crack, which eventually leads to destruction of the specimen. It can be seen from 405 the figures that the concrete specimen is not destroyed immediately after the peak 406 stress, as the internal cracks are still in the microcrack stage, a macrocrack has not 407 been formed yet. This illustrates that concrete is a quasi-brittle heterogeneous 408 material, not an entirely brittle material, where its microstructure controls the 409 development of cracks. After reaching the tensile strength, the development of 410 internal cracks is intensified and aggravated, and the material performance 
411 significantly declines, underpinned by the formation of macrocracks. After this

412 point, the energy required for crack development is much less than the energy

413 required for crack propagation before the peak stress. Comparing Fig. 9 (b) and Fig.

$41410(\mathrm{~b})$, it is seen that time for microcracks generation in RSCC specimen is less than

415 in the ordinary SCC before the peak stress, and the microcrack development in

416 RSCC before the peak stress is faster. This shows that the incorporation of rubber

417 particles increases the overall defects in the structure and weakens the material

418 performance of the pre-peak phase, which also supports the conclusion in section

419 5.1. In the initial phase, microcracks appear throughout the specimen, not just

420 located at the position which will lead to macrocrack and the final failure of the

421 specimen. The macrocrack location is closely related to the spatial distribution of

422 the concrete components as suggested by the crack location in Figs. 10 (b), 11 (b)

423 and 12 (b); different realisation of the randomly distributed components will result

424 in a different crack pattern.

\subsubsection{Effect of rubber content on the development of macroscopic cracks}

426 Based on the analysis of 5.2.1, this section selects RSCC-0 and RSCC-15 specimen to

427 conduct a comparative analysis on the development process of macroscopic cracks to

428 further analyse the influence of rubber incorporation on the development of

429 macrocracks in concrete. The crack development after the peak stress of the selected

430 mesoscale specimen, corresponding to time points of $s_{1} \sim s_{4}$, is shown in Figs. 9 (c) and

43112 (c). As can be seen from these figures, the rate of macrocrack propagation after the 

microcracks in RSCC-15 are more dispersed at the same time. At the moment $\mathrm{s}_{4}$, the concentrated internal damage in specimen RSCC-0 is very high and the overall failure

436 of the material is observed, while the concentrated internal damage in specimen RSCC-

43715 is lower, indicating that the addition of rubber improves the overall toughness of the material and reduces the rate of macrocrack propagation.

\subsection{Effect of rubber content on crack morphology}

Figure 13 shows the morphology of the final failure surfaces for the four specimen types.

441 As can be seen in Fig. 13(a), the crack in RSCC-0 mainly occurs at the transition

442 interface between aggregate and mortar. During the crack development process, some 443 big voids will appear in the crack surface, as the crack avoids aggregates which cannot 444 be damaged. The number of such voids in Figs. 13 (b), (c) and (d) is significantly 445 smaller, indicating that the addition of rubber optimizes the gradation of concrete 446 aggregate, and the area of the interface transition zone is significantly increased. As can 447 be seen from Figs. 13(b), (c), (d), the number of large voids in the whole crack surface 448 of the specimen decreases, and more small size voids appear with the increase of rubber 449 content. This is due to the increase of the number of rubber particles, which enables the 450 crack to develop and extend at both A-M ITZ and R-M ITZ. The size decrease of the 451 voids indicates that the crack will preferentially develop at the R-M ITZ, and the smaller 452 size rubber particles can be easily bypassed. At the same time, because of the size of 
453 the rubber particle is smaller, the energy needed to bypass a rubber particle is much

454 lower than a bigger size aggregate. Therefore, the crack surface will produce some 455 smaller size voids when the specimen contains many rubber particles. The final crack 456 pattern also conforms to the hypothesis and setting of the mechanical parameters of the 457 material. Rubber particles and coarse aggregate are linear elastic materials, which will 458 not be damaged. Elastoplastic damage can occur in the mortar, A-M ITZ, and R-M ITZ. 459 The mechanical properties of A-M ITZ and R-M ITZ are inferior to mortar, so the 460 cracks mainly occur in these two areas. Since rubber is an organic material and mortar 461 is an inorganic material, the mechanical properties of the interface transition zone 462 between two different types of materials are inferior to the interface transition zone 463 between the same type of material. And it is known that the porosity of R-M ITZ is 464 significantly higher than that of A-M ITZ [4]. It is further known that the strength of 465 mortar materials is closely related to the porosity [36,37]. When the porosity is high, 466 the material strength is low, and when the porosity is low, the material strength is high. 467 Therefore, the interfacial transition zone between rubber and mortar is the weakest 468 interface in the material; the crack will preferentially develop at the R-M ITZ, followed 469 by the A-M ITZ.

\section{Conclusions}

471 Based on uniaxial tension test results of rubberized concrete, this paper explores the 472 application of mesoscale modelling to improve understanding of damage and failure of 
473 such materials in view of their potential for economic and environmental benefits. The

474 following conclusions can be drawn from the work:

475 1. By comparing test and numerical simulation results for stress-strain response and 476 crack pattern and location, it is demonstrated that the proposed 3D mesoscale model 477 can be used to analyse damage evolution and crack development in RSCC. In addition, 478 the mesoscale model has the potential to be used in analysis of other mechanical 479 properties of RSCC.

480 2. The results of the RSCC prism test and numerical simulation show that the 481 toughness of RSCC is improved compared with that of SCC, and the bearing capacity 482 is reduced. When the rubber particle gradation is the same, with the increase of rubber 483 content, the strength of the specimen decreases, the toughness of the specimen increases, 484 and the overall damage rate of the material is reduced.

485 3. The final morphology of the uniaxial tensile cracks of RSCC shows that the 486 incorporation of rubber particle reduces the failure rate. Due to the incorporation of 487 rubber particles, the pores and defects of the concrete are filled, the gradation of the 488 concrete sand and aggregate is optimized, and the porosity of the test piece is reduced 489 to some extent. However, the total area of the interfacial transition zone is increased 490 significantly. The special properties of rubber materials lead to extremely high 491 interfacial porosity between rubber particles and mortar. The porosity brought by the 492 increased interfacial transition zone is much higher than that reduced by the 493 optimization of particle grading, so the overall strength of the material will still decline. 
494 4. The R-M ITZ is the weakest constituent of rubberized concrete due to high porosity 495 and weak cohesion between two different types of material. Microcracks are easy to 496 nucleate and grow in this region, and eventually develop into macrocracks resulting in 497 the overall failure of the material. 
499 The research is based upon the work supported by the National Natural Science 500 Foundation of China (Grant No. 51779085). 


\section{Reference}

502 [1] E.N. N., S.A. B., Rubber-Tire Particles as Concrete Aggregate, J. Mater. Civ. Eng. 5 (1993) 478-496. doi:10.1061/(ASCE)0899-1561(1993)5:4(478).

504 [2] H.A. Toutanji, The use of rubber tire particles in concrete to replace mineral 505 aggregates, Cem. Concr. Compos. 18 (1996) 135-139.

[3] İ.B. Topcu, Assessment of the brittleness index of rubberized concretes, Cem. Concr. Res. 27 (1997) 177-183.

[4] G. Li, M.A. Stubblefield, G. Garrick, J. Eggers, C. Abadie, B. Huang, Development of waste tire modified concrete, Cem. Concr. Res. 34 (2004) $2283-2289$.

511 [5] F. Hernandez-Olivares, G. Barluenga, M. Bollati, B. Witoszek, Static and dynamic behaviour of recycled tyre rubber-filled concrete, Cem. Concr. Res.

514 [6] F. Hernández-Olivares, G. Barluenga, B. Parga-Landa, M. Bollati, B.

Witoszek, Fatigue behaviour of recycled tyre rubber-filled concrete and its implications in the design of rigid pavements, Constr. Build. Mater. 21 (2007) $1918-1927$.

518 [7] L. Zheng, X.S. Huo, Y. Yuan, Experimental investigation on dynamic properties of rubberized concrete, Constr. Build. Mater. 22 (2008) 939-947.

520 [8] F. Liu, G. Chen, L. Li, Y. Guo, Study of impact performance of rubber reinforced concrete, Constr. Build. Mater. 36 (2012) 604-616. 
522 [9] W.H. Yung, L.C. Yung, L.H. Hua, A study of the durability properties of waste tire rubber applied to self-compacting concrete, Constr. Build. Mater. 41 (2013) $665-672$.

[10] O. Youssf, J.E. Mills, R. Hassanli, Assessment of the mechanical performance of crumb rubber concrete, Constr. Build. Mater. 125 (2016) 175-183.

[11] F. Liu, G. Zhong, X. Xia, L. Li, Mechanical analysis of rubberized concrete subjected to uniaxial compression on meso-level, J. Build. Mater. 13 (2010) $733-738$.

[12] Z.H. Xie, Y.C. Guo, Q.Z. Yuan, P.Y. Huang, Mesoscopic numerical computation of compressive strength and damage mechanism of rubber concrete, Adv. Mater. Sci. Eng. 2015 (2015).

[13] P. Grassl, D. Grégoire, L.R. Solano, G. Pijaudier-Cabot, Meso-scale modelling 49 (2012) 1818-1827.

[14] S.Y. Alam, P. Kotronis, A. Loukili, Crack propagation and size effect in concrete using a non-local damage model, Eng. Fract. Mech. 109 (2013) 246261.

[15] P. Grassl, M. Jirásek, Damage-plastic model for concrete failure, Int. J. Solids Struct. 43 (2006) 7166-7196.

[16] P. Badel, V. Godard, J.-B. Leblond, Application of some anisotropic damage model to the prediction of the failure of some complex industrial concrete 
structure, Int. J. Solids Struct. 44 (2007) 5848-5874.

544 [17] S.-M. Kim, R.K.A. Al-Rub, Meso-scale computational modeling of the plasticdamage response of cementitious composites, Cem. Concr. Res. 41 (2011) $339-358$.

[18] J. Lubliner, J. Oliver, S. Oller, E. Oñate, A plastic-damage model for concrete, Int. J. Solids Struct. 25 (1989) 299-326.

[19] J. Lee, G.L. Fenves, Plastic-damage model for cyclic loading of concrete

551 [20] W. Tian, F. Dang, Y. Xie, Quantitative study on crack of meso-damage and fracture concrete based on CT technique, Sadhana. 40 (2015) 263-276.

553 [21] X.Q. Zhou, H. Hao, Modelling of compressive behaviour of concrete-like materials at high strain rate, Int. J. Solids Struct. 45 (2008) 4648-4661.

[22] R.R. Pedersen, A. Simone, L.J. Sluys, Mesoscopic modeling and simulation of

[23] Z. Tu, Y. Lu, Mesoscale modelling of concrete for static and dynamic response the dynamic tensile behavior of concrete, Cem. Concr. Res. 50 (2013) 74-87.

[24] Y. Huang, Z. Yang, W. Ren, G. Liu, C. Zhang, 3D meso-scale fracture (2011) 197-213. modelling and validation of concrete based on in-situ X-ray Computed Tomography images using damage plasticity model, Int. J. Solids Struct. (2015). doi:10.1016/j.ijsolstr.2015.05.002. 
564 [25] B.D. Barnes, S. DIAMOND, W.L. Dolch, Micromorphology of the interfacial zone around aggregates in Portland cement mortar, J. Am. Ceram. Soc. 62 (1979) 21-24.

567 [26] E.J. Garboczi, D.P. Bentz, Analytical formulas for interfacial transition zone properties, Adv. Cem. Based Mater. 6 (1997) 99-108.

569 [27] J.G.M. Van Mier, M.R.A. van Vliet, T.K. Wang, Fracture mechanisms in particle composites: statistical aspects in lattice type analysis, Mech. Mater. 34 (2002) 705-724.

[28] X.Q. Zhou, H. Hao, Mesoscale modelling of concrete tensile failure mechanism at high strain rates, Comput. Struct. 86 (2008) 2013-2026.

[29] Y. Lu, Z. Song, Z. Tu, Analysis of dynamic response of concrete using a

[30] H. Chen, B. Xu, Y.L. Mo, T. Zhou, Behavior of meso-scale heterogeneous concrete under uniaxial tensile and compressive loadings, Constr. Build. Mater. 178 (2018) 418-431.

[31] J.G.M. Van Mier, M.R.A. Van Vliet, Influence of microstructure of concrete on size/scale effects in tensile fracture, Eng. Fract. Mech. 70 (2003) 2281-2306.

[32] A. Caballero, C.M. López, I. Carol, 3D meso-structural analysis of concrete specimens under uniaxial tension, Comput. Methods Appl. Mech. Eng. 195 (2006) 7182-7195. 
585
[33] X. Wang, M. Zhang, A.P. Jivkov, Computational technology for analysis of 3D meso-structure effects on damage and failure of concrete, Int. J. Solids Struct. 80 (2016) 310-333.

[34] Z. Yang, W. Ren, M. Mostafavi, S.A. Mcdonald, T.J. Marrow, Characterisation of 3D fracture evolution in concrete using in-situ X-ray computed tomography testing and digital volume correlation, in: VIII Int. Conf. Fract. Mech. Concr. Concr. Struct., Toledo, Spain CIMNE, 2013: pp. 1-7.

[35] Y. Huang, Z. Yang, W. Ren, G. Liu, C. Zhang, 3D meso-scale fracture modelling and validation of concrete based on in-situ X-ray Computed Tomography images using damage plasticity model, Int. J. Solids Struct. 67 (2015) 340-352.

[36] X. Chen, S. Wu, J. Zhou, Influence of porosity on compressive and tensile strength of cement mortar, Constr. Build. Mater. 40 (2013) 869-874.

[37] Y. Wu, X. Zhou, Y. Gao, L. Zhang, J. Yang, Effect of soil variability on bearing capacity accounting for non-stationary characteristics of undrained shear strength, Comput. Geotech. 110 (2019) 199-210. 


\section{List of figure captions}

604 Fig. 1. Test device and specimen

605 Fig. 2. The uniaxial stress-strain curve with damage plasticity

606 Fig. 3. Flowchart of random aggregates, rubber particles and voids generation

607 Fig. 4. Concrete mesoscale models with different compositions

608 Fig. 5. Stress-strain curve of each group RSCC specimen under uniaxial tension

609 Fig. 6. Crack pattern and location of each group RSCC specimen under uniaxial tension

610 Fig. 7. Stress-strain curve of RSCC under tension test

611 Fig. 8. Simulation result of RSCC with different rubber content under uniaxial tension

612 Fig.9. Simulation result of RSCC-0 specimen under uniaxial tension

613 Fig.10. Simulation result of RSCC-5 specimen under uniaxial tension

614 Fig.11. Simulation result of RSCC-10 specimen under uniaxial tension

615 Fig.12. Simulation result of RSCC-15 specimen under uniaxial tension

616 Fig. 13. Final crack morphology of RSCC specimens with different rubber content 


\section{List of table captions}

618 Table 1 The mix proportion of $\operatorname{RSCC}\left(\mathrm{kg} / \mathrm{m}^{3}\right)$

619 Table 2 Coarse aggregate size distribution

620 Table 3 Material parameters for RSCC mesoscale model

621 
Table 1 The mix proportion of RSCC $\left(\mathrm{kg} / \mathrm{m}^{3}\right)$

\begin{tabular}{ccccccccc}
\hline Specimen & Cement & Fly ash & $\begin{array}{c}\text { Silica } \\
\text { Fume }\end{array}$ & Water & Water & Rubber & Sand & Gravel \\
& & & Reducer & particle & & \\
\hline RSCC-0 & 385 & 139 & 26 & 200 & 7.5 & 0 & 1080 & 800 \\
RSCC-5 & 385 & 139 & 26 & 200 & 7.5 & 52 & 1080 & 672 \\
RSCC-10 & 385 & 139 & 26 & 200 & 7.5 & 104 & 1080 & 542 \\
RSCC-15 & 385 & 139 & 26 & 200 & 7.5 & 156.5 & 1080 & 413 \\
\hline
\end{tabular}

623

624

Table 2 Coarse aggregate size distribution

\begin{tabular}{cc}
\hline Sieve size $(\mathrm{mm})$ & Total passed percentage (\%) \\
\hline 10 & $100 \%$ \\
8 & $60 \%$ \\
6 & 0 \\
\hline
\end{tabular}

625

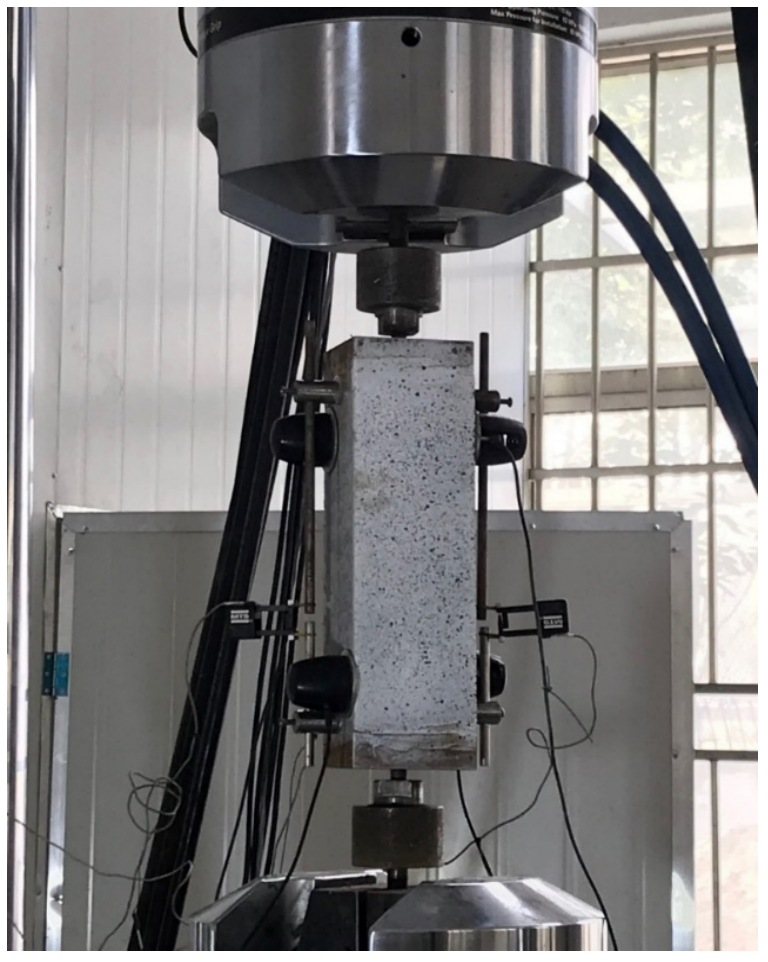

Fig. 1. Test device and specimen 


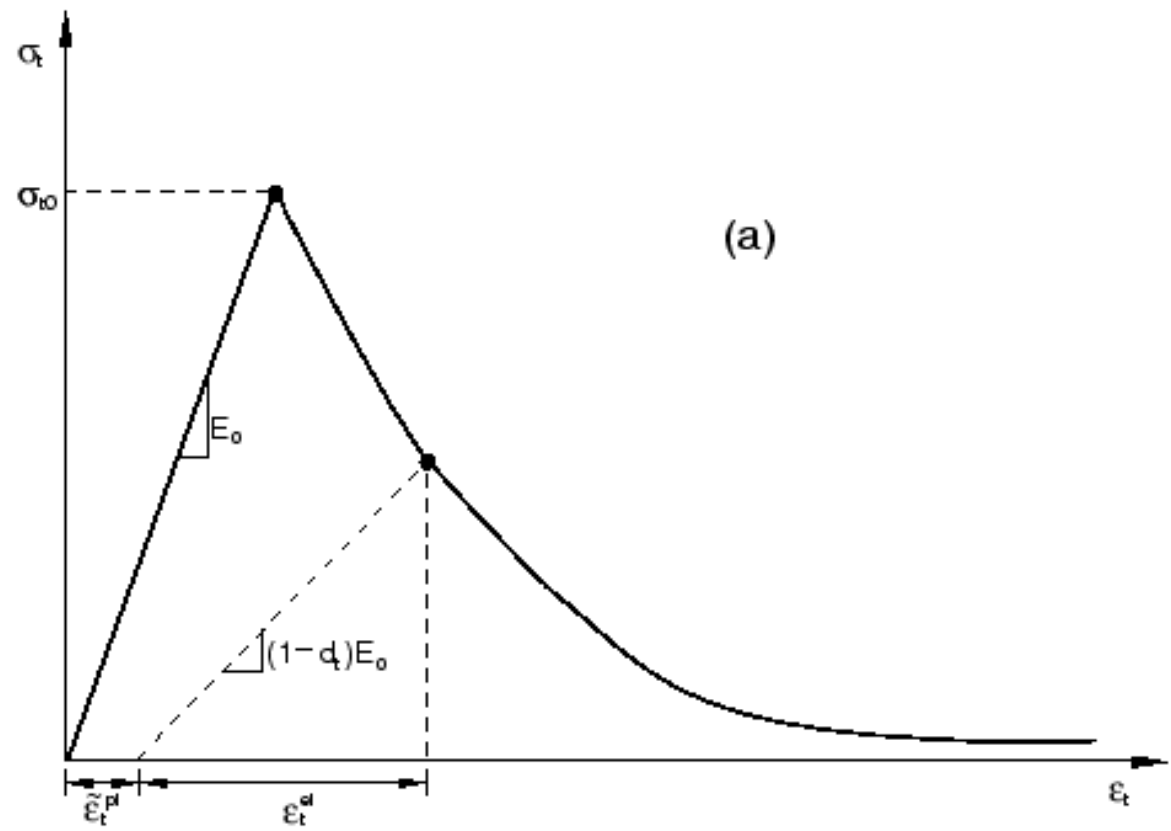

(a) Concrete response under uniaxial tension

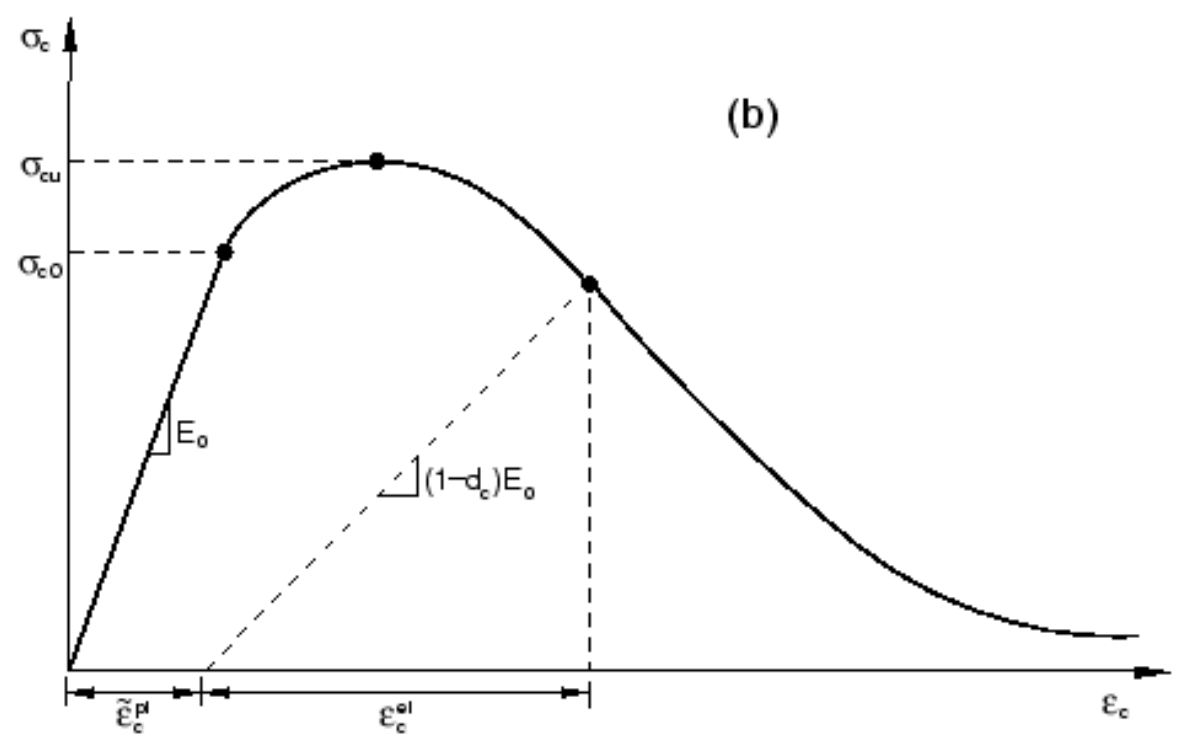

(b) Concrete response under uniaxial compression 


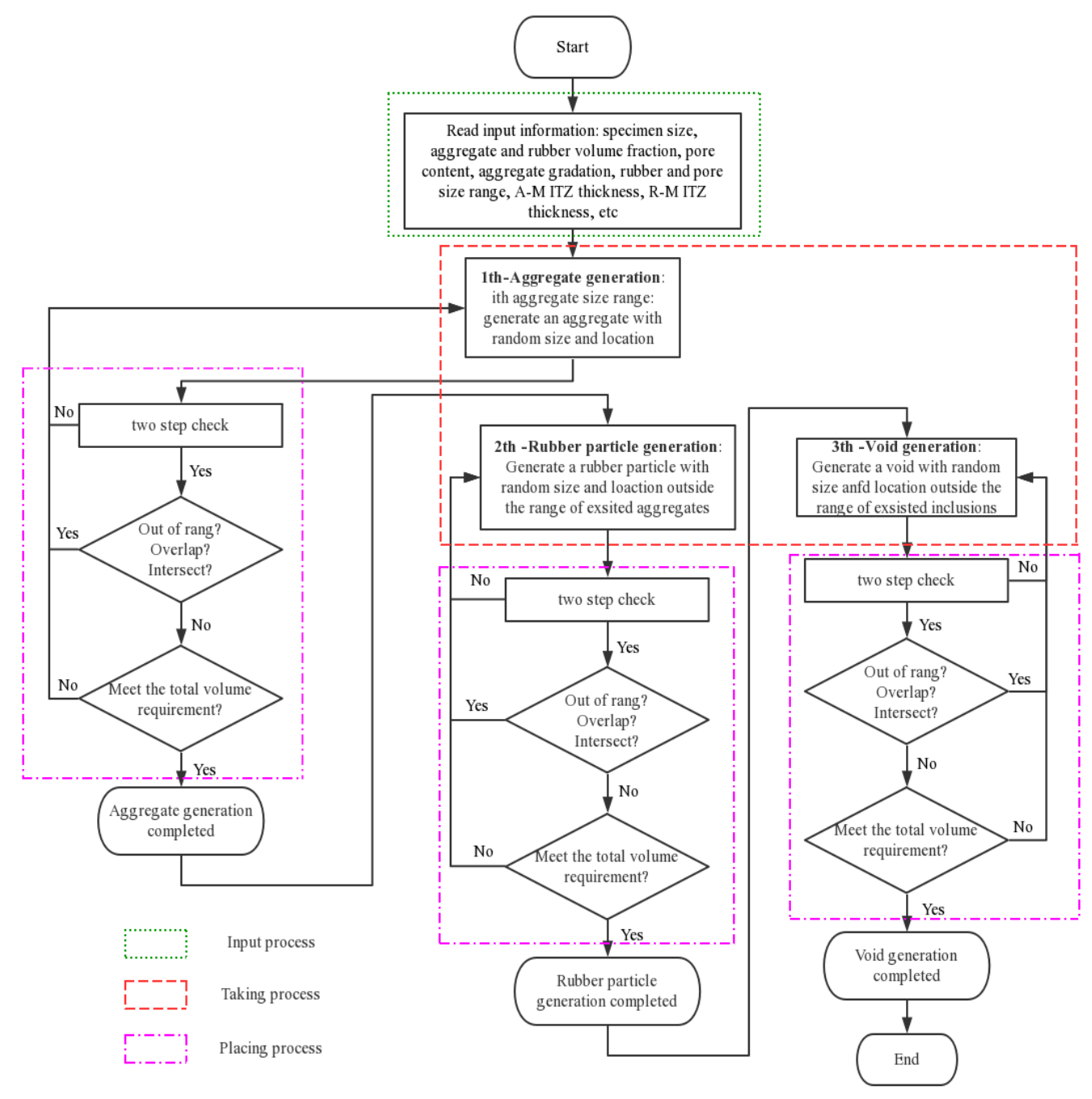

635

Fig. 3. Flowchart of random aggregates, rubber particles and voids generation 


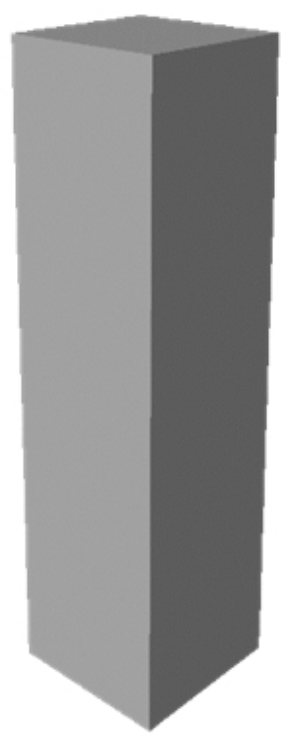

(a) Concrete prism

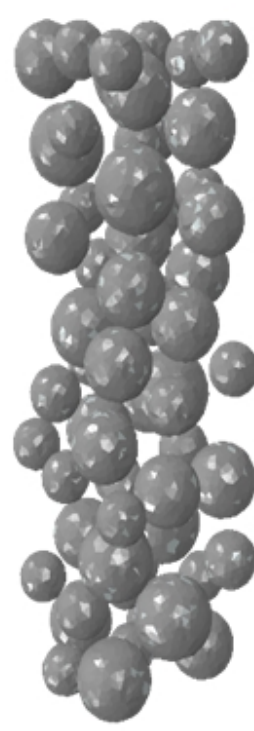

(b) RSCC-0

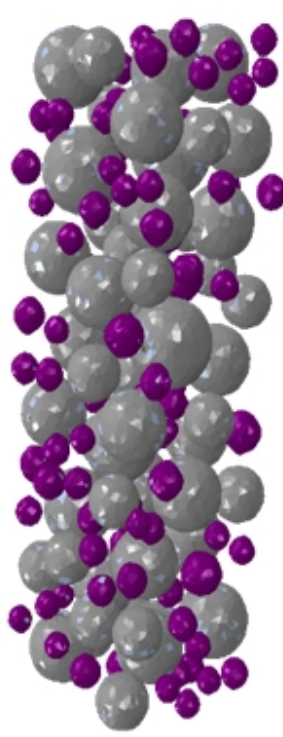

(C) RSCC-5

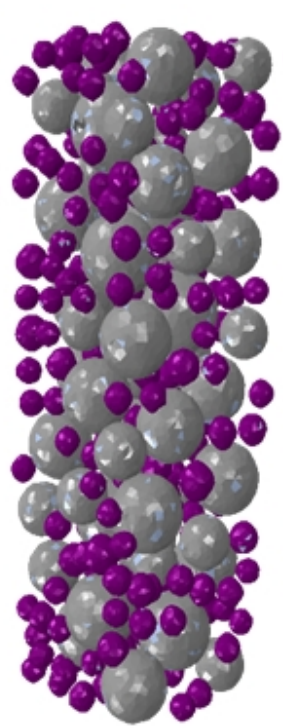

(d) RSCC-10

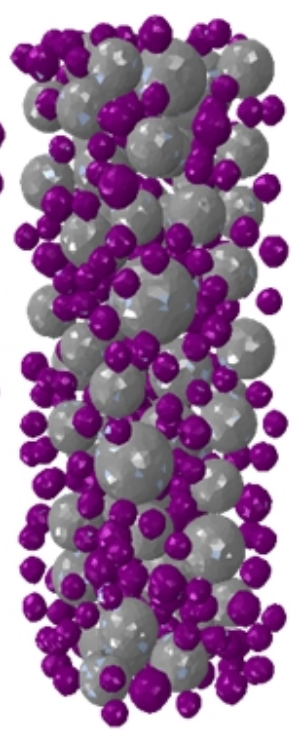

(e) RSCC-15

Fig. 4. Concrete mesoscale models with different compositions. Gray spheres are coarse 
Table 3 Material parameters for RSCC meso-scale model

\begin{tabular}{cccccc} 
& Tensile strength & Compressive & Young's modulus & Poisson's & Density \\
& $(\mathrm{MPa})$ & strength & $(\mathrm{GPa})$ & ratio & $\left(\mathrm{Kg} / \mathrm{m}^{\wedge} 3\right)$ \\
& $(\mathrm{MPa})$ & & & \\
\hline Mortar & 4.4 & 60 & 42 & 0.2 & 2200 \\
Coarse aggregate & -- & -- & 40 & 0.2 & 2600 \\
Rubber particle & -- & -- & 7 & 0.4 & 1050 \\
A-M ITZ & 3 & 45 & 21 & 0.2 & 1800 \\
R-M ITZ & 1.5 & 25 & 12.5 & 0.2 & 1500 \\
\hline
\end{tabular}

643

644 


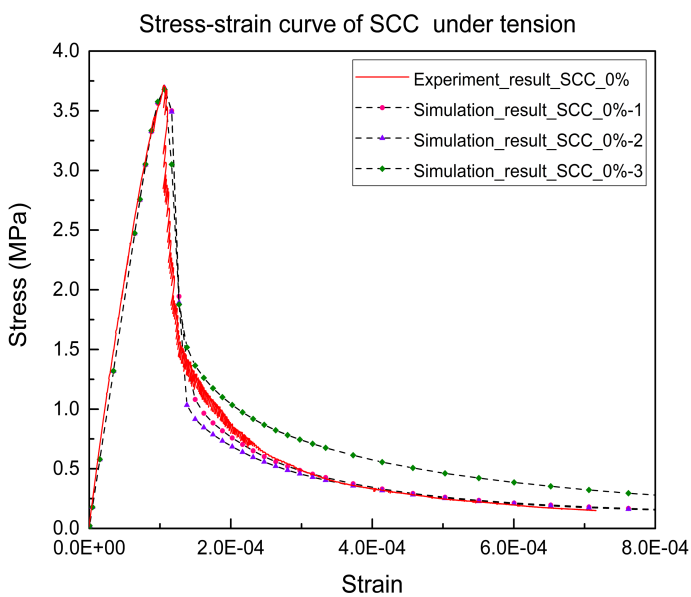

647
Stress-strain curve of RSCC with $5 \%$ rubber under tension

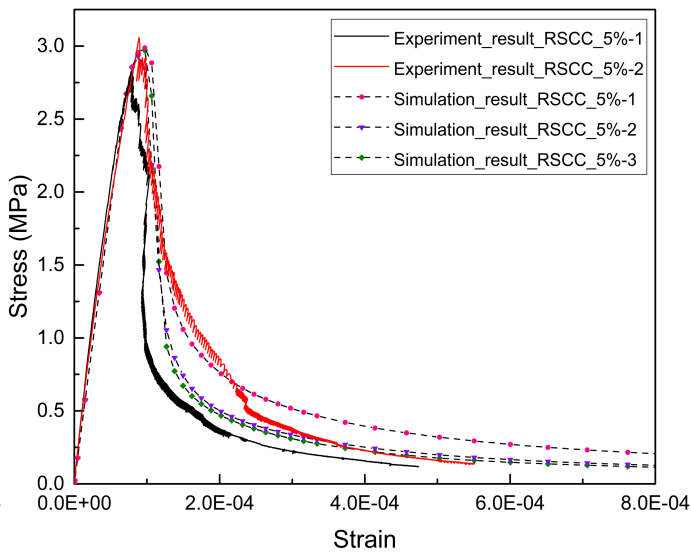

(b) Stress-strain curve of RSCC-5

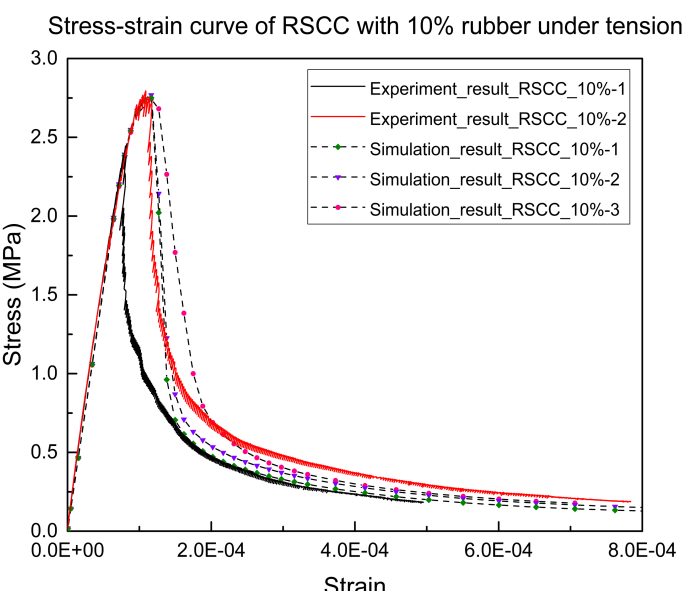

649

(c) Stress-strain curve of RSCC-10

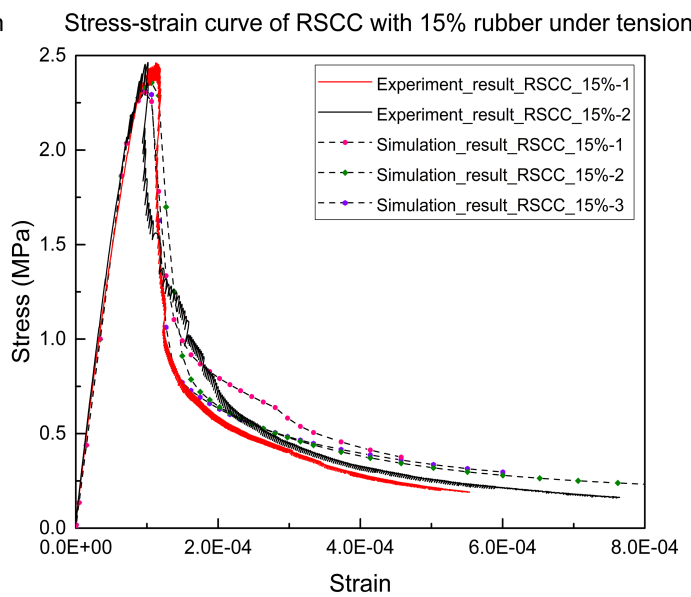

(d) Stress-strain curve of RSCC-15 
651
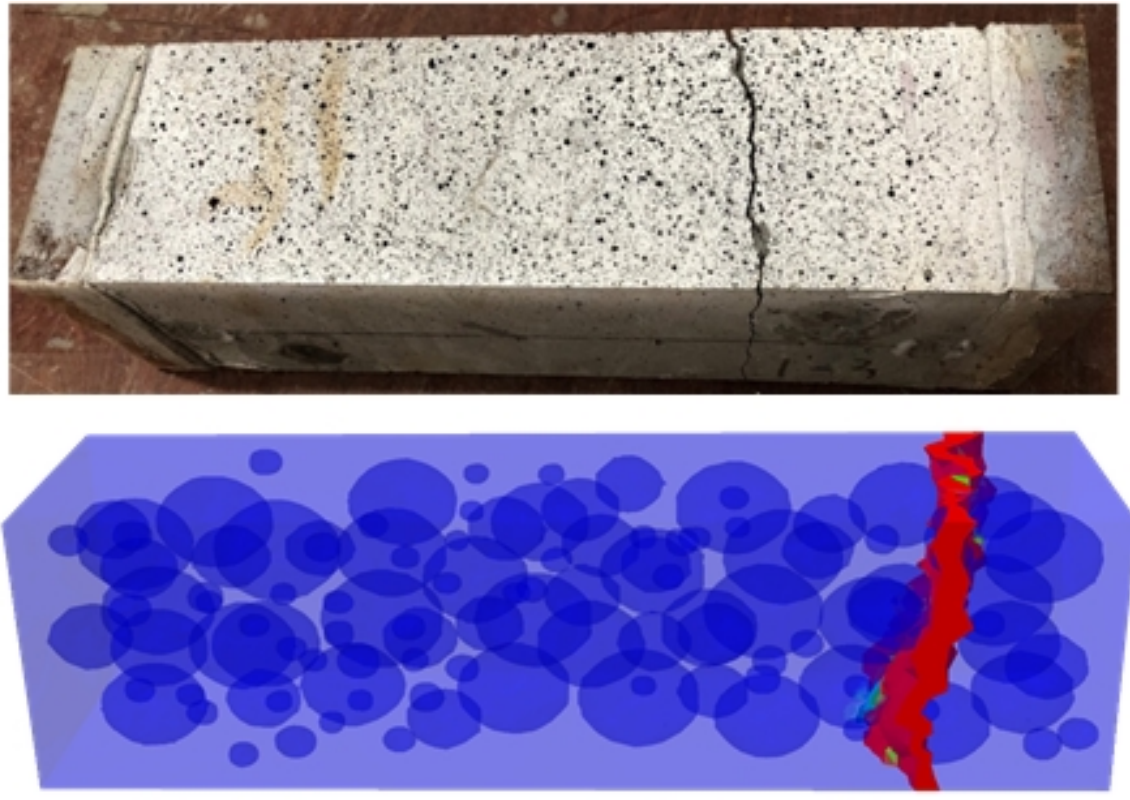

(a) RSCC-0 specimen with no rubber particle content
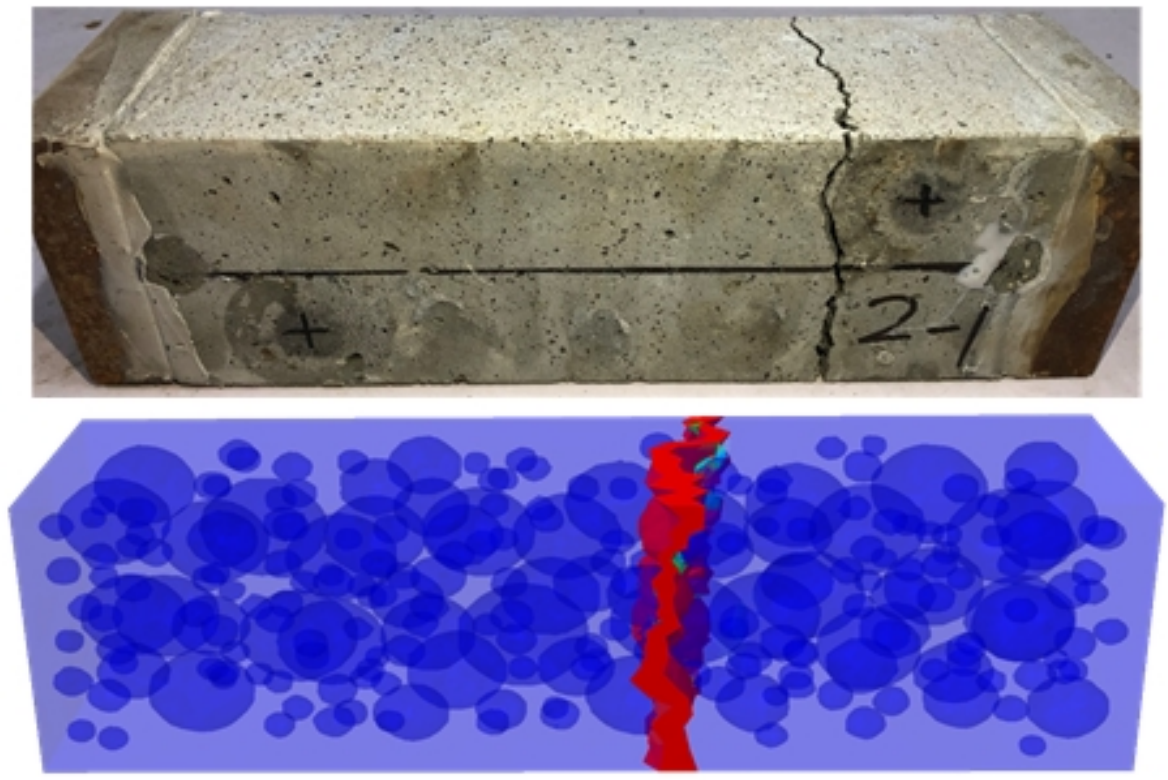

(b) RSCC-5 specimen with 5\% rubber particle content 

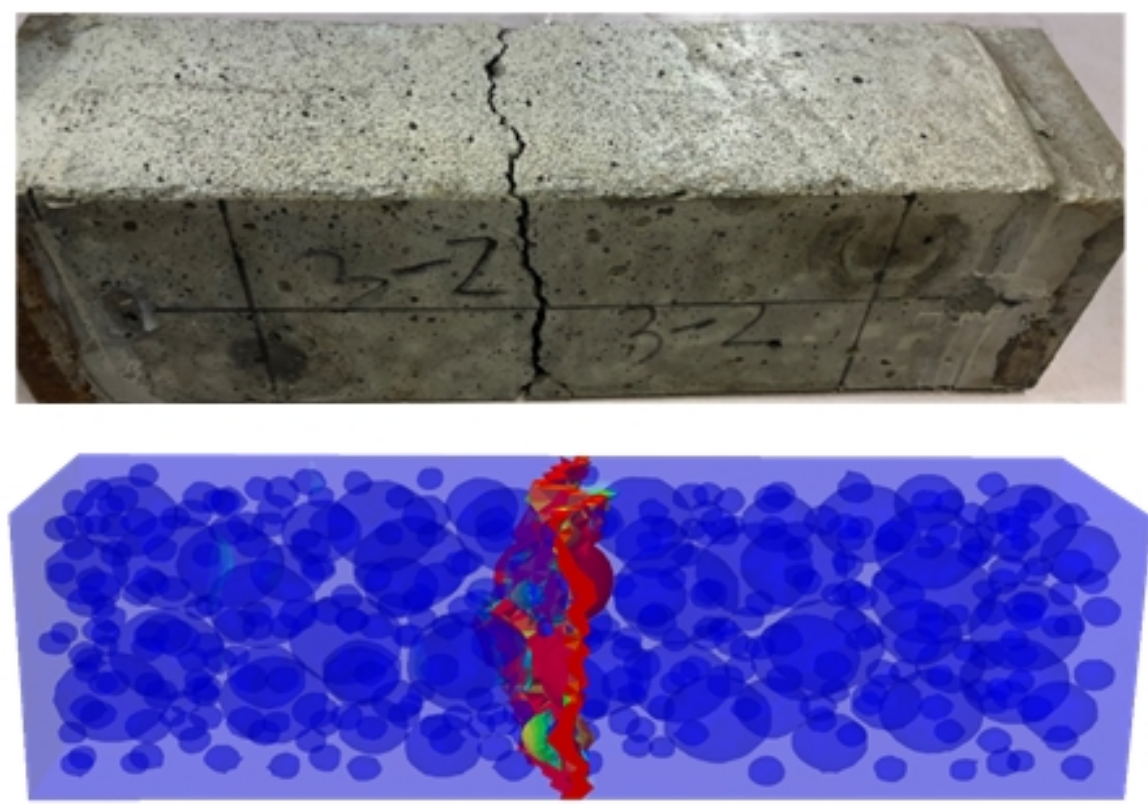

(c) RSCC-10 specimen with $10 \%$ rubber particle content
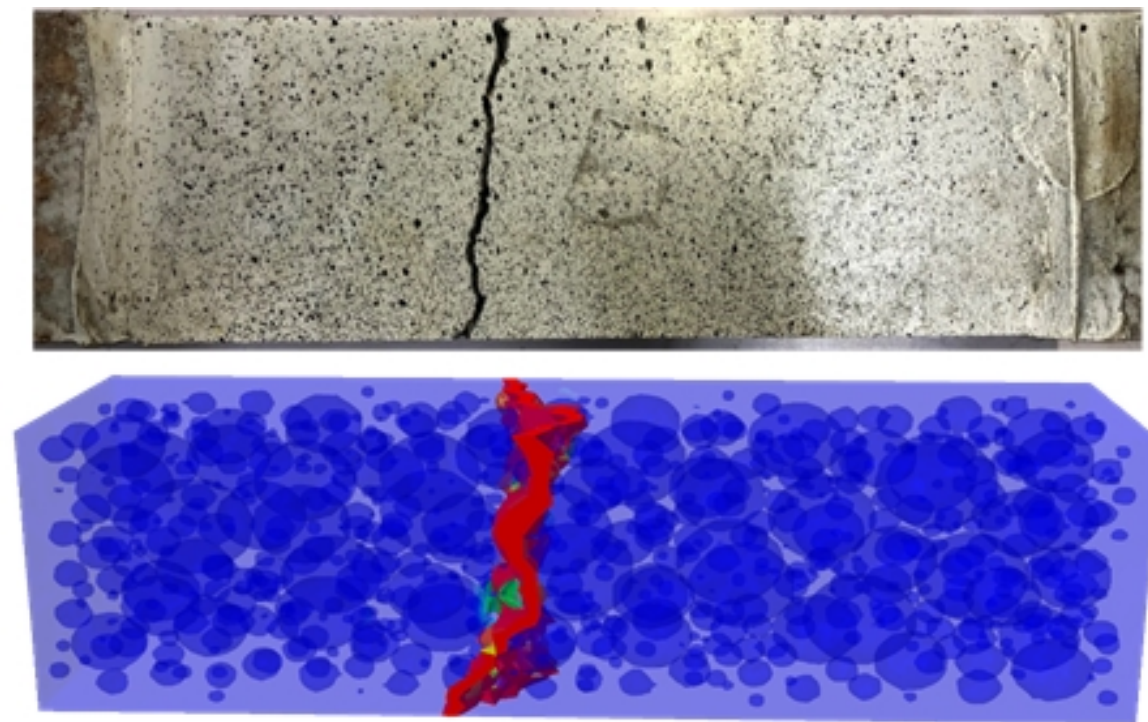

(d) RSCC-15 specimen with $15 \%$ rubber particle content 
Experiment result of concrete specimen with different content

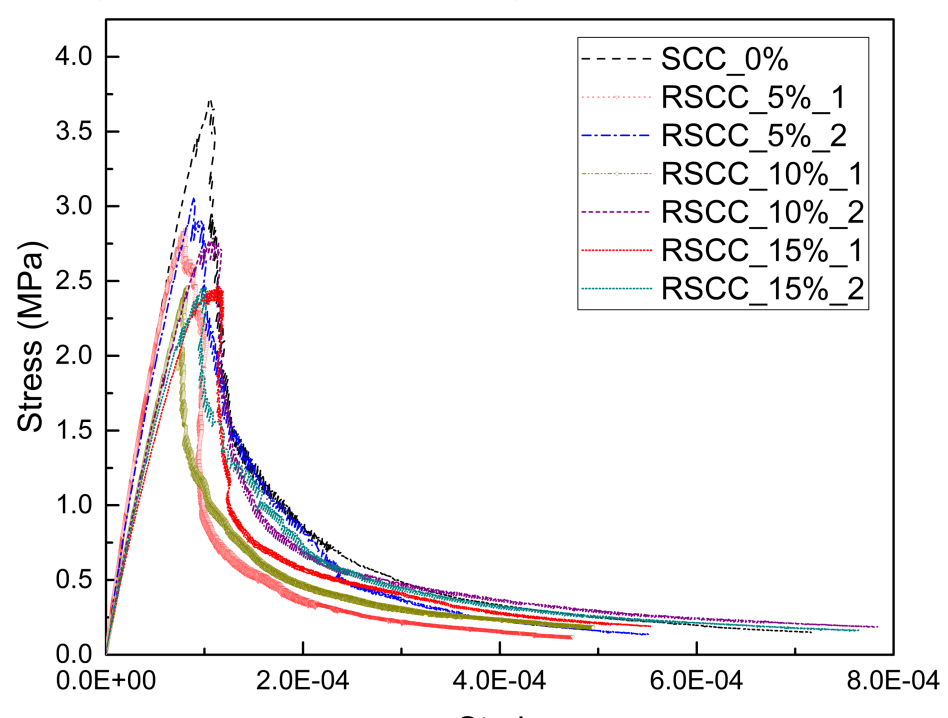

Strain

Fig. 7. Stress-strain curve of RSCC under tension test

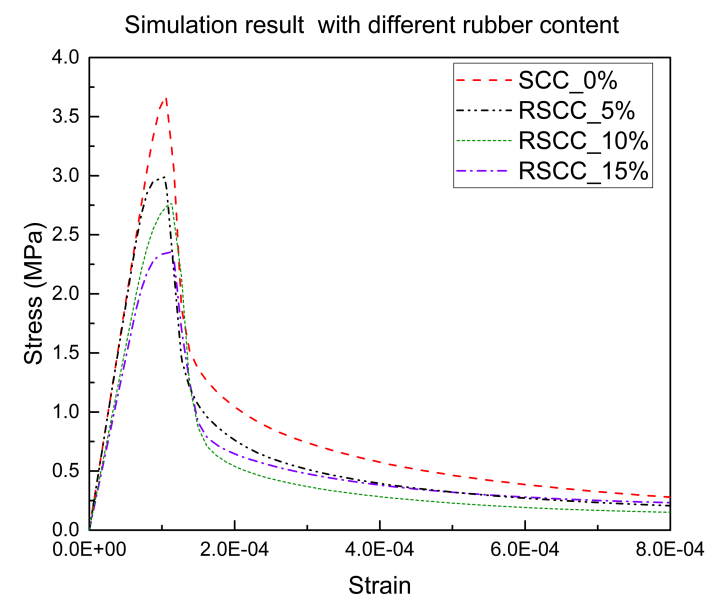

(a) Stress-strain curve of RSCC under tension simulation

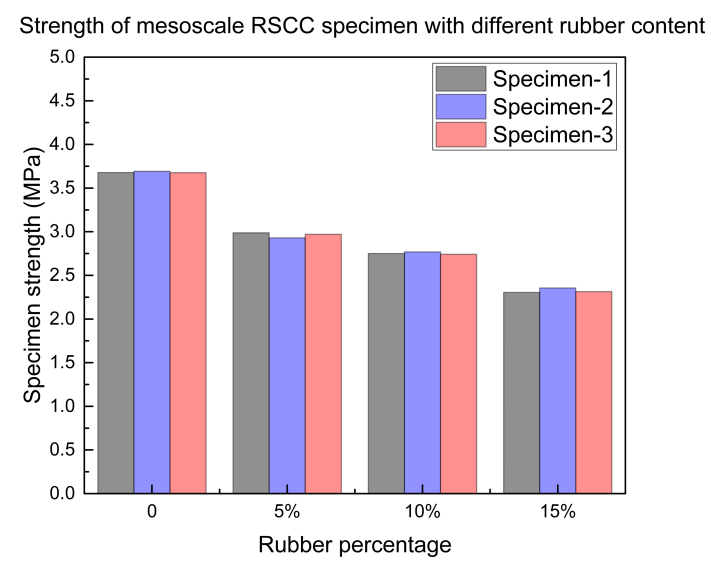

(b) Column chart of specimen strength with different rubber content

Fig. 8. Simulation result of RSCC with different rubber content under uniaxial tension 
666

667

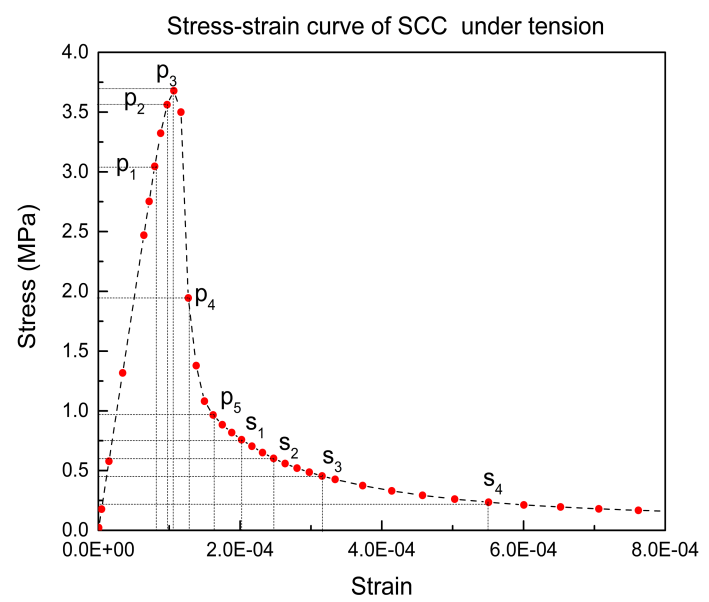

(a) Stress-strain curve of RSCC-0
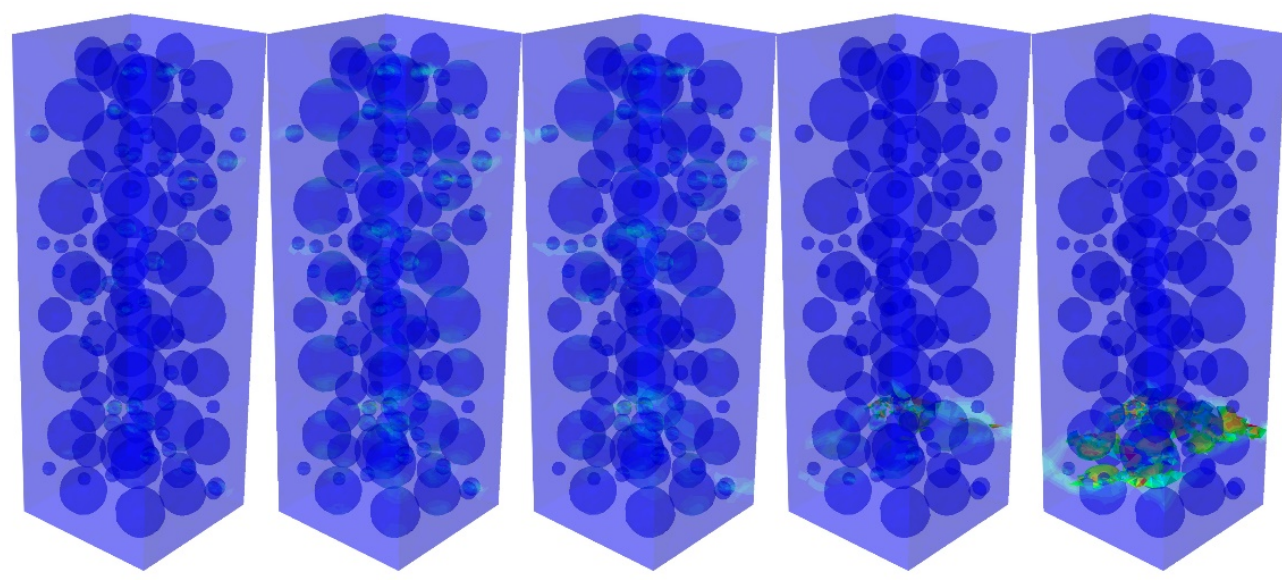

668

p1

p2

p3

p4

p5

669

(b) Microcrack development status of mesoscale RSCC-0 specimen at time p0, p1, p2, p3, p4, p5

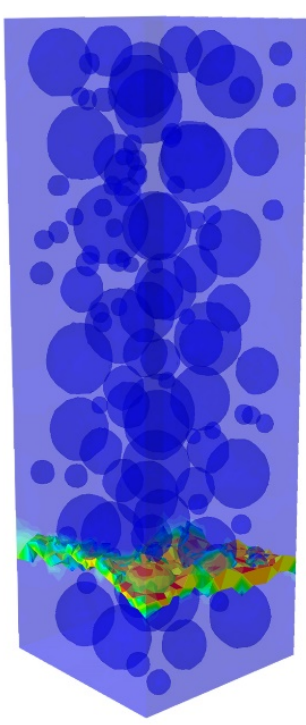

S 1

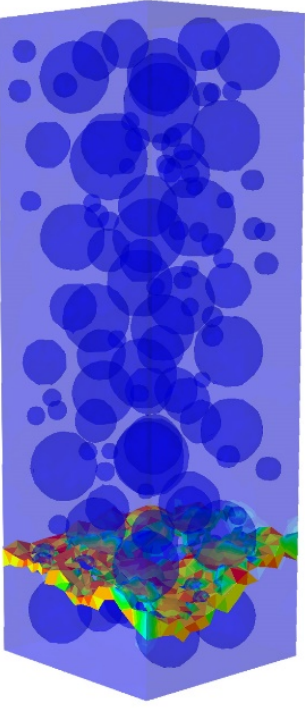

s2

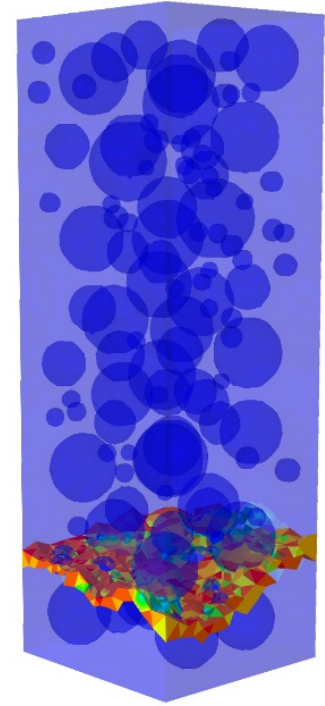

s3

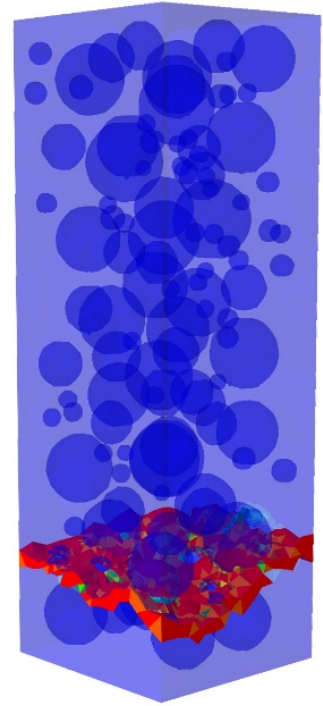

s4 
(c) Macrocrack development status of mesoscale RSCC-0 specimen at time s1, s2, s3, s4

Fig. 9. Simulation result of RSCC-0 specimen under uniaxial tension

673

674

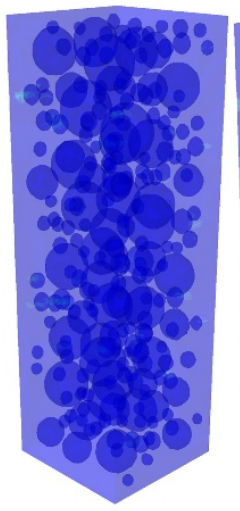

p0

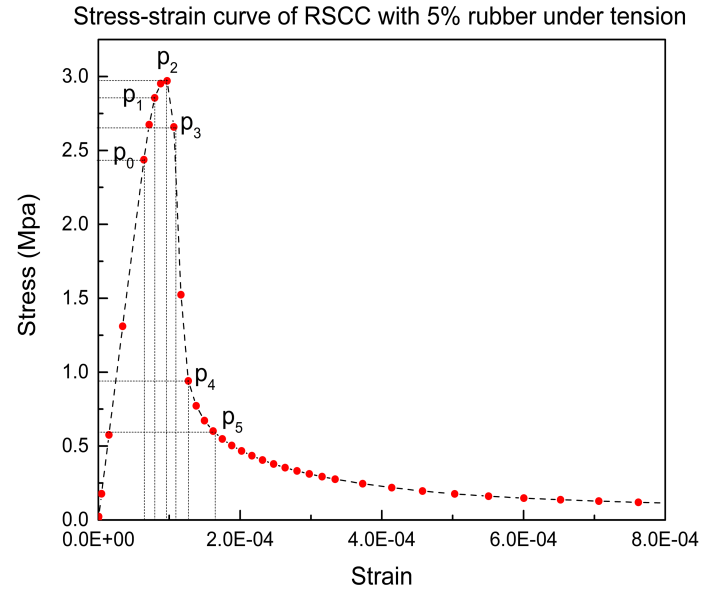

(a) Stress-strain curve of RSCC-5

(b) Microcrack development status of mesoscale RSCC-5 specimen at time p0, p1, p2, p3, p4, p5

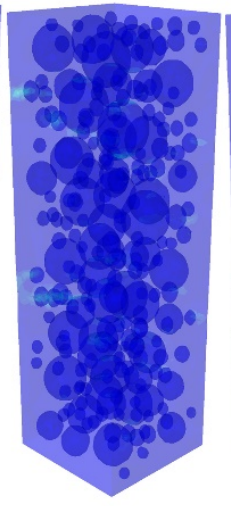

p1

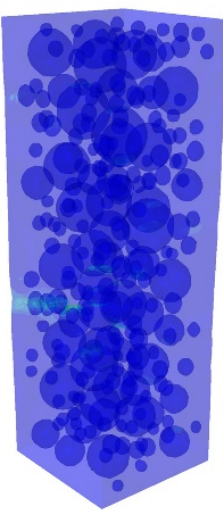

p2

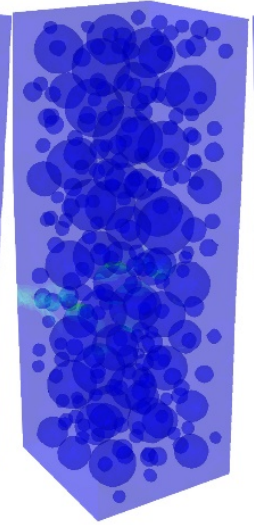

p3

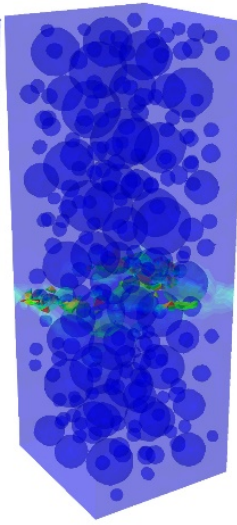

p4

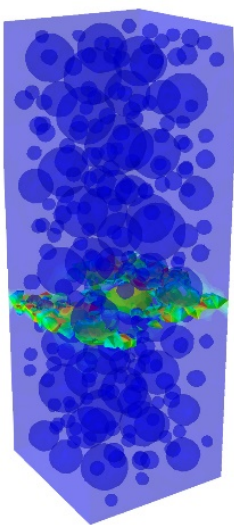

p5

Fig. 10. Simulation result of RSCC-5 specimen under uniaxial tension

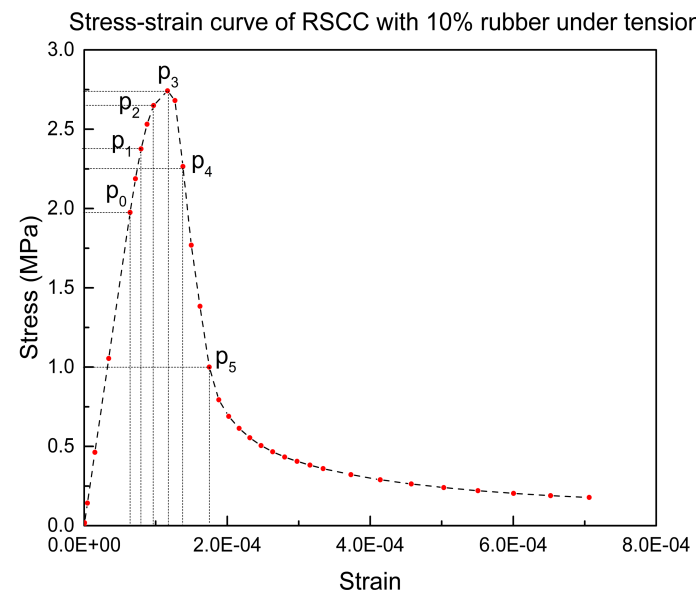

(a) Stress-strain curve of RSCC-5 


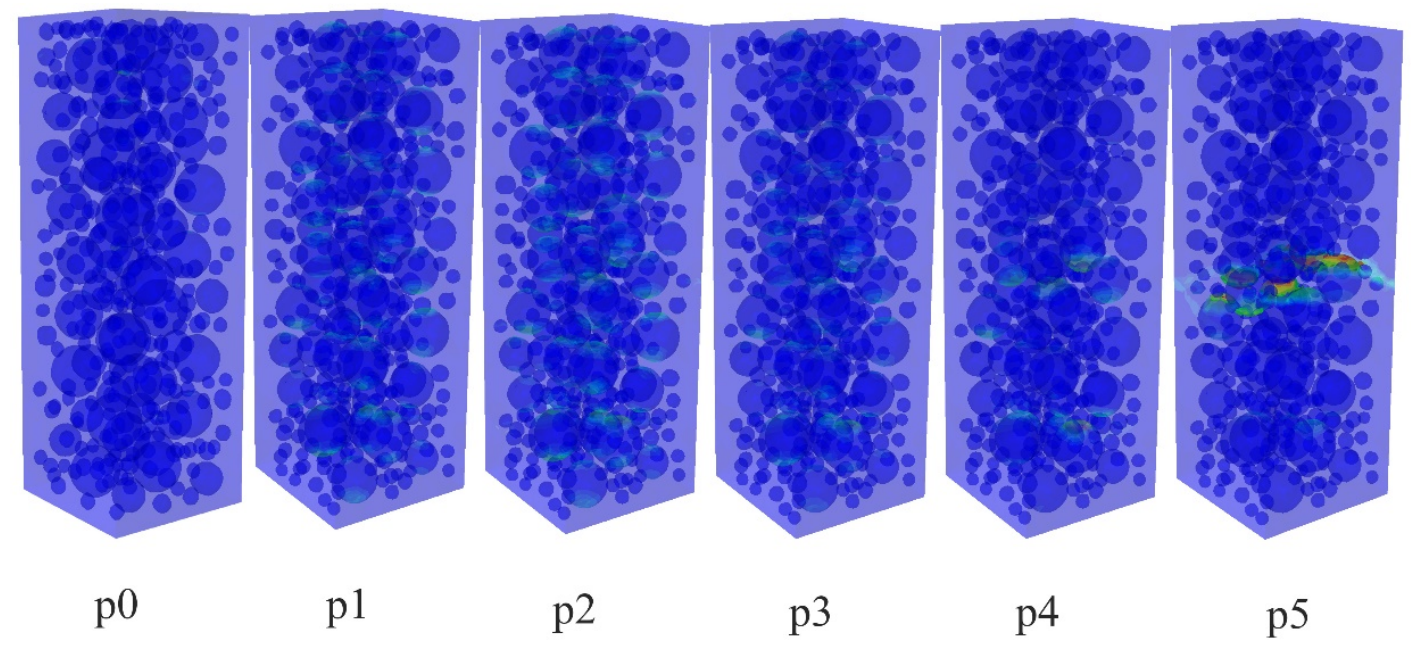

681

682

683

(b) Microcrack development status of mesoscale RSCC-10 specimen at time p0, p1, p2, p3, p4,

684 p5

685

686

687

688

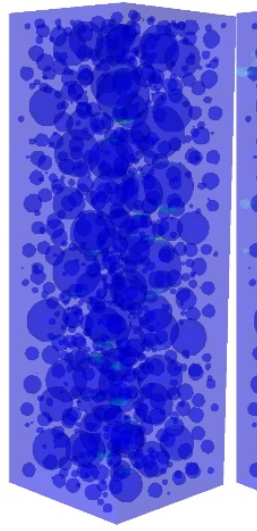

p0

Fig. 11. Simulation result of RSCC-10 specimen under uniaxial tension

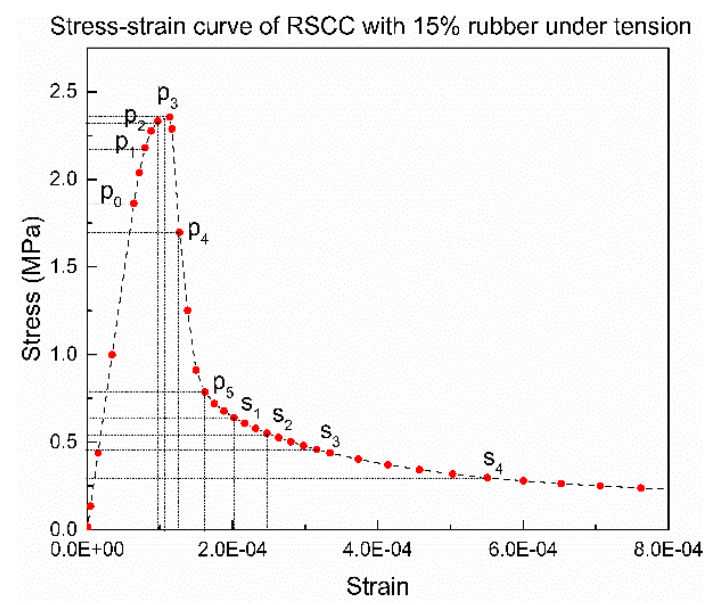

(a) Stress-strain curve of RSCC-5

690

(b) Microcrack development status of mesoscale RSCC-15 specimen at time p0, p1, p2, p3, p4, 


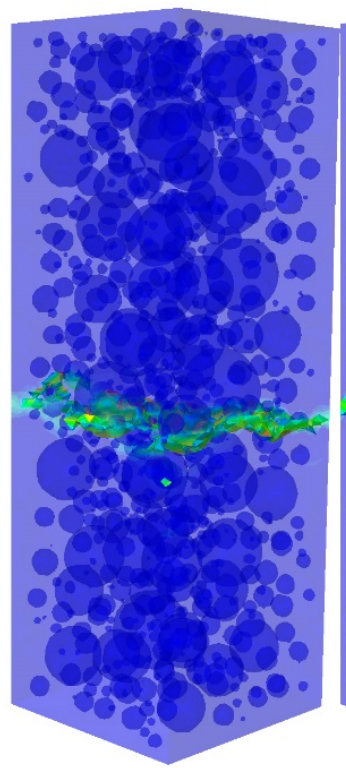

S 1

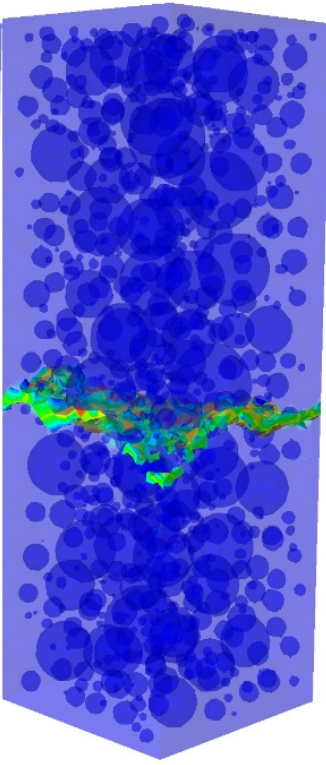

s2

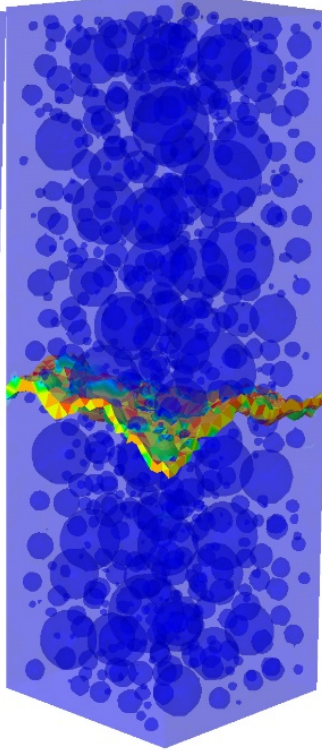

s3

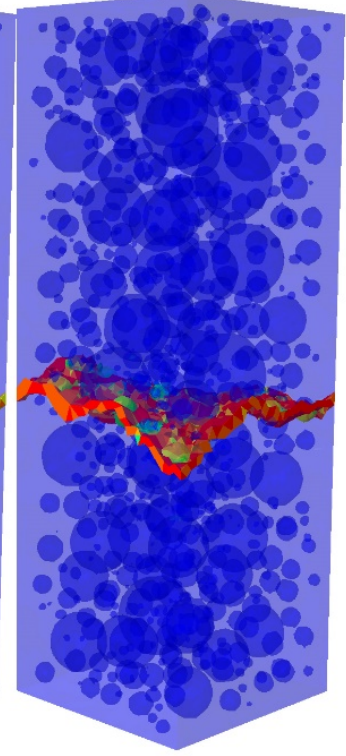

S4
692

693 694

(c) Macrocrack development status of mesoscale RSCC-15 specimen at time s1, s2, s3, s4 Fig. 12. Simulation result of RSCC-15 specimen under uniaxial tension

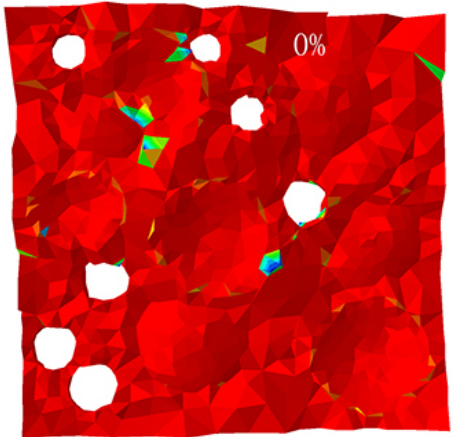

(a)RSCC-0

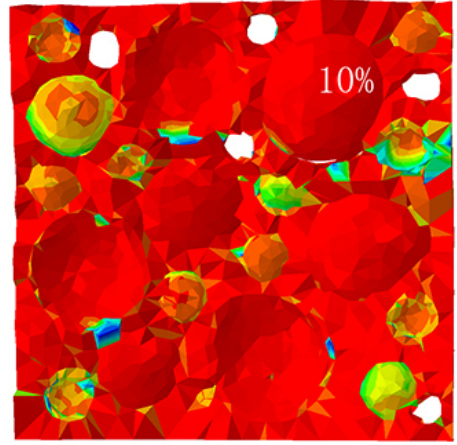

(c)RSCC-10

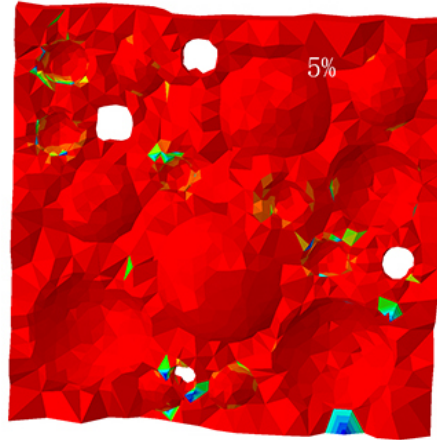

(b)RSCC-5

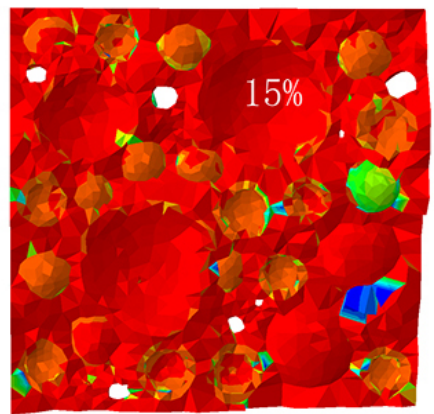

(d)RSCC-15 